\title{
Heptavalinamide A, an extensively $N$-methylated linear nonapeptide from a cyanobacterium Symploca sp. and development of a highly sensitive analysis of $N, N$-dimethylvaline by LCMS
}

Rei Suo,${ }^{\dagger} \|$ Ryuichi Watanabe, ${ }^{\S}$ Kentaro Takada, ${ }^{\ddagger}$ Toshiyuki Suzuki, ${ }^{\S}$ Hiroshi Oikawa, ${ }^{\S}$ Shiro Itoi, $\|$ Haruo Sugita, ${\text { land Shigeki Matsunaga }{ }^{*}, \dagger}^{\prime}$

${ }^{\dagger}$ Laboratory of Aquatic Natural Products Chemistry, Graduate School of Agricultural and Life Sciences, The University of Tokyo, 1-1-1 Bunkyo-ku, Tokyo 113-8657, Japan

"College of Bioresource Sciences, Nihon University, 1866 Kameino, Fujisawa, Kanagawa 2520880, Japan

${ }^{\S}$ National Research Institute of Fisheries Science, 2-12-4 Fukuura, Kanazawa-ku, Yokohama, Kanagawa 236-8648, Japan

${ }^{\ddagger}$ School of Marine Biosciences, Kitasato University, 1-15-1 Kitasato, Minami-ku, Sagamihara, Kanagawa 252-0373, Japan

\section{Table of Contents}

Experimental Section

Table S1. NMR Data for conformer A of heptavalinamide $\mathrm{A}(\mathbf{1})$ in $\mathrm{CD}_{3} \mathrm{OH}$.

Table S2. NMR Data for conformer B of heptavalinamide A (1) in $\mathrm{CD}_{3} \mathrm{OH}$.

Figure S1-2. ${ }^{1} \mathrm{H}$ NMR spectrum of Heptavalinamide $\mathrm{A}(1)$ in $\mathrm{CD}_{3} \mathrm{OH}$.

Figure S3. ${ }^{13} \mathrm{C}$ NMR spectrum of Heptavalinamide $\mathrm{A}(\mathbf{1})$ in $\mathrm{CD}_{3} \mathrm{OH}$.

Figure S4-5. COSY spectra of Heptavalinamide A (1) in $\mathrm{CD}_{3} \mathrm{OH}$.

Figure S6-9. TOCSY spectra of Heptavalinamide A (1) in $\mathrm{CD}_{3} \mathrm{OH}$.

Figure S10-12. HSQC spectra of Heptavalinamide $\mathrm{A}(\mathbf{1})$ in $\mathrm{CD}_{3} \mathrm{OH}$.

Figure S13. HMBC spectrum of Heptavalinamide $\mathrm{A}(\mathbf{1})$ in $\mathrm{CD}_{3} \mathrm{OH}$.

Figure S14-15. ROESY spectra of Heptavalinamide A (1) in $\mathrm{CD}_{3} \mathrm{OH}$.

Figure S16-18. HMBC spectra of Heptavalinamide A (1) in $\mathrm{CD}_{3} \mathrm{OH}$.

Figure S19. ROESY spectrum of Heptavalinamide $\mathrm{A}(\mathbf{1})$ in $\mathrm{CD}_{3} \mathrm{OH}$.

Figure S20. HMBC spectrum of Heptavalinamide A (1) in $\mathrm{CD}_{3} \mathrm{OH}$.

Figure S21-22. ROESY spectra of Heptavalinamide A (1) in $\mathrm{CD}_{3} \mathrm{OH}$.

Figure S23-S24. ROESY spectra of Heptavalinamide A (1) in $\mathrm{CD}_{3} \mathrm{OH}$.

Figure S25. ESI-MS/MS spectrum of Heptavalinamide A (1).

Figure S26-28. LCMS chromatograms of Marfey's derivatives.

Figure S29. LCMS chart of $p$-bromophenacyl esters of $N, N-\mathrm{Me}_{2} \mathrm{Val}$.

Figure S30. LCMS chart of $p$-bromophenacyl esters of $N, N-\mathrm{Me}_{2} \mathrm{Val}-\mathrm{N}$-oxide. 


\section{Experimental Section}

\section{General Experimental Procedures}

Optical rotations were measured on a Jasco DIP-1000 polarimeter. UV spectra were measured on a Shimadzu BioSpec-1600 spectrophotometer. NMR spectra were measured on a Bruker AVANCE III spectrometer $\left({ }^{1} \mathrm{H}: 800 \mathrm{MHz}\right)$ and referenced to the solvent peak: $\delta_{\mathrm{H}} 3.30$ and $\delta_{\mathrm{C}} 49.0$ for methanol- $d_{3}$. ESI mass spectra were recorded on a JEOL JMS-T100LC mass spectrometer. LCMS experiments were performed on a Shimadzu LC-20AD solvent delivery system and interfaced to a Bruker amaZon SL mass spectrometer. The results of the MTT assay was recorded with a Molecular Devices SPECTRA max M2.

\section{Collection, Extraction and Isolation}

The marine cyanobacterium was collected from reefs inside Kabira Bay, Okinawa, Japan, at low tide in June 2017. The collected cyanobacterium (180 g) were homogenized in $\mathrm{MeOH}$ and extracted with $\mathrm{MeOH}$ and $\mathrm{MeOH} / \mathrm{CHCl}_{3}(1: 1)$. The extracts were combined, concentrated in vacuo, and partitioned between $\mathrm{H}_{2} \mathrm{O}$ and $\mathrm{CHCl}_{3}$. The $\mathrm{CHCl}_{3}$ layer was further partitioned between $n$-hexane and $\mathrm{MeOH}-\mathrm{H}_{2} \mathrm{O}(9: 1)$. The aqueous $\mathrm{MeOH}$ fraction was subjected to ODS flash column chromatography with stepwise elution of 5\% $\mathrm{MeOH}$, 
$50 \% \mathrm{MeOH}, 90 \% \mathrm{MeOH}, \mathrm{MeOH}$, and $\mathrm{CHCl}_{3} / \mathrm{MeOH}(1: 1)$. The $50 \% \mathrm{MeOH}$ fraction and the $90 \% \mathrm{MeOH}$ fraction were first purified by RP-HPLC on a COSMOSIL $5 \mathrm{C}_{18}$-AR-II column with gradient elution from $50 \% \mathrm{MeOH}$ to $100 \% \mathrm{MeOH}$ in the presence of $0.5 \%$ $\mathrm{AcOH}$ to afford a fraction. The fraction was further purified by RP-HPLC on a COSMOSIL $5 \mathrm{C}_{18}$-AR-II column with gradient elution from $45 \% \mathrm{MeCN}$ to $65 \% \mathrm{MeCN}$ in the presence of $0.5 \% \mathrm{AcOH}$ to give heptavalinamide $\mathrm{A}(\mathbf{1}, 0.5 \mathrm{mg})$.

Heptavalinamide $\boldsymbol{A}$ (1): colorless solid; $[\alpha]_{\mathrm{D}}-70$ ( $c$ 0.01, $\left.\mathrm{MeOH}\right)$; UV (MeOH) $\lambda_{\max }(\log \varepsilon) 257$ (4.4), 215 (4.3); ${ }^{1} \mathrm{H}$ and ${ }^{13} \mathrm{C}$ NMR data, see Table 1; HRESIMS $m / z$ 1104.7410 $[\mathrm{M}+\mathrm{Na}]^{+}\left(\right.$calcd for $\left.\mathrm{C}_{58} \mathrm{H}_{99} \mathrm{~N}_{9} \mathrm{O}_{10} \mathrm{Na}, 1104.7413\right)$

\section{DNA Isolation, PCR Amplification, Cloning and Sequencing}

Small pieces of freshly collected cyanobacterium were preserved in RNA later (Qiagen) for species identification. Genomic DNA was extracted from the DNeasy PowerBiofilm Kit (Qiagen) following the manufacturer's specifications. The 16S rRNA genes were PCR-amplified from the extracted DNA using the cyanobacterial-specific primer, CYA359F (5'-GGGGAATYTTCCGCAATGGG-3'), and CYA781R (5'GACTACAGGGGTATCTAATCCCTTT-3'). ${ }^{1}$ The PCR reaction contained $2 \mu \mathrm{L}$ of DNA template, $5 \mu \mathrm{L}$ of $10 \times$ buffer for Ex Taq, $4 \mu \mathrm{L}$ of dNTPs, $3 \mu \mathrm{L}$ of each primer $(0.3 \mu \mathrm{M}), 1$ 
unit of Ex Taq (TAKARA), and $\mathrm{H}_{2} \mathrm{O}$ for a total volume of $50 \mu \mathrm{L}$. The PCR reaction was performed on an $\mathrm{T} 100^{\mathrm{TM}}$ Thermal Cycler (Bio-Rad) as follows: initial denaturation at $98{ }^{\circ} \mathrm{C}$ for $30 \mathrm{~s}, 35$ cycles of denaturation $98{ }^{\circ} \mathrm{C}$ for $10 \mathrm{~s}$, annealing at $55{ }^{\circ} \mathrm{C}$ for $30 \mathrm{~s}$, extension at $72{ }^{\circ} \mathrm{C}$ for $1 \mathrm{~min}$, and a final elongation for $10 \mathrm{~min}$ at $72{ }^{\circ} \mathrm{C}$. The PCR products were electrophoresed on $2 \%$ agarose gel in $1 \times$ TAE buffer, stained with ethidium bromide, and purified by NucleoSpin ${ }^{\circledR}$ Gel and PCR Clean-up (TaKaRa). Purified PCR products were cloned with pGEM-T-Easy-Vector-Systems (Promega) following the manufacturer's specifications. Clones were screened for inserts by PCR amplification with M13F and M13R primers, and several white clones were sequenced by a commercial firm using the M13 primers. The sequencing data is as follows:

5'-CGAAAGCCTGACGGAGCAATACCGCGTGAGGGAGGAAGGCTCTTGGGTC GTAAACCTCTTTTGTCAGGGAAGAAAACAAGGACGGTACCTGAAGAATCAG CATCGGCTAACTCCGTGCCAGCAGCCGCGGTAATACGGAGGATGCAAGCGTT ATCCGGAATTATTGGGCGTAAAGCGTCCGCAGGTGGCTCTTCAAGTCTGCCG TTAAAGGCCAGGGCTCAACTCTGGTTAGGCGGTGGAAACTGTAGAGCTAGA GTGCAGGAGGGGTAGAGGGAATTCCCGGTGTAGCGGTGAAATGCGTAGATAT CGGGAAGAACATCGGTGGCGAAGGCGCTCTACTGGACTGCAACTGACACTC AGGGACGAAAGCTAGGGGAGCG-3' 


\section{Synthesis of $p$-bromophenacyl esters of $N, N$-dimethyl D- and L-valine- $N$-oxide}

To a solution of L-valine $(1 \mathrm{mg})$ in $\mathrm{H}_{2} \mathrm{O}(100 \mu \mathrm{L})$ was added $\mathrm{NaBH}_{3} \mathrm{CN}(5 \mathrm{mg})$, and the mixture was kept in an ice-water bath for $30 \mathrm{~min}$ to cool down. Formaldehyde (37\% solution, $200 \mu \mathrm{L}$ ) was then added, and the reaction mixture was stirred in an ice-water bath for $30 \mathrm{~min}^{2}$ The reaction mixture was quenched with $2 \mathrm{~N} \mathrm{HCl}$, and concentrated to afford a crude amino acid $(4 \mathrm{mg})$, which was used in the next reaction without further purification. To a solution of the crude $N, N$-dimethyl-L-valine in DMF $(150 \mu \mathrm{L})$ was added $p$-bromophenacyl bromide $(1 \mathrm{mg})$ in the presence of KF $(1 \mathrm{mg})$ and stirred at $\mathrm{rt}$ for $40 \mathrm{~min}$. The reaction mixture was diluted with $\mathrm{H}_{2} \mathrm{O}$ and extracted with EtOAc. The EtOAc layer was concentrated to give $p$-bromophenacyl ester of $N, N$ dimethyl-L-valine (2 mg). To a solution of $p$-bromophenacyl ester of $N, N$-dimethyl-Lvaline $(100 \mu \mathrm{g})$ in $\mathrm{MeOH}(100 \mu \mathrm{L})$ was added Oxone $(1 \mathrm{mg})$, and the solution was stirred at $\mathrm{rt}$ for $2 \mathrm{~h}$. The mixture was diluted with $\mathrm{H}_{2} \mathrm{O}$ and extracted with $\mathrm{MeOH}$ to give $p$ bromophenacyl ester of $N, N$-dimethyl-L-valine- $N$-oxide (2b, $1.1 \mathrm{mg}) . p$-Bromophenacyl ester of $N, N$-dimethyl-D-valine- $N$-oxide was synthesized in the same manner starting with D-valine (2a, $1.2 \mathrm{mg})$. 


\section{Preparation of $p$-bromophenacyl ester of $N, N$-dimethylvaline- $N$-oxide from}

\section{hydrolysate of 1}

The compound $1(30 \mu \mathrm{g})$ was hydrolyzed in $6 \mathrm{~N} \mathrm{HCl}$ at $110{ }^{\circ} \mathrm{C}$ for $12 \mathrm{~h}$. The solution was concentrated and then treated in the same manner, as described above.

\section{Marfey's Analysis of Pro, $N$-Me-Val and $N$-Me-Phe using $\mathrm{C}_{18}$ column}

Compound $1(30 \mu \mathrm{g})$ was hydrolyzed in $6 \mathrm{~N} \mathrm{HCl}$ at $110^{\circ} \mathrm{C}$ for $12 \mathrm{~h}$. The solution was concentrated and redissolved in $\mathrm{H}_{2} \mathrm{O}(100 \mu \mathrm{L})$. To the solution was added $1 \% \mathrm{D}-$ FDAA in acetone $(100 \mu \mathrm{L})$ and $1 \mathrm{M} \mathrm{NaHCO}_{3}$ in $\mathrm{H}_{2} \mathrm{O}(20 \mu \mathrm{L})$. The resulting solution was kept at $55^{\circ} \mathrm{C}$ for $30 \mathrm{~min}$. After neutralization with $2 \mathrm{~N} \mathrm{HCl}(10 \mu \mathrm{L})$, the reaction mixture was analyzed by LCMS at a flow rarte of $0.5 \mathrm{~mL} \mathrm{~min}^{-1}$ on COSMOSIL $\pi$-nap column. Gradient elution was performed using solvent $\mathrm{A}\left(0.5 \%\right.$ acetic acid in $\left.\mathrm{H}_{2} \mathrm{O}\right)$ and solvent $\mathrm{B}$ $(0.45 \%$ acetic acid in $\mathrm{MeCN})$ with the following linear gradient combination: $15 \%$ to $50 \%$ $\mathrm{MeCN}$ for $60 \mathrm{~min}$.

Retention time for standard amino acids (min): L-Pro (16.5), D-Pro (14.6), $N$-Me-L-Val (27.1), $N$-Me-D-Val (25.2), $N$-Me-L-Phe (27.7), $N$-Me-D-Phe (26.5).

Retention time of the amino acids from hydrolysate of 1: $16.5 \mathrm{~min}\left(\mathrm{~m} / \mathrm{z} 368[\mathrm{M}+\mathrm{H}]^{+}\right.$, Pro), $27.1 \mathrm{~min}\left(\mathrm{~m} / \mathrm{z} 384[\mathrm{M}+\mathrm{H}]^{+}, N\right.$-Me-Val), $27.7 \mathrm{~min}\left(\mathrm{~m} / z 432[\mathrm{M}+\mathrm{H}]^{+}, N-\mathrm{Me}-\mathrm{Phe}\right)$. 


\section{Determination of absolute configuration of $N, N$-dimethylvaline- $N$-oxide by LCMS}

analysis

The compound $1(30 \mu \mathrm{g})$ was hydrolyzed in $6 \mathrm{~N} \mathrm{HCl}$ at $110{ }^{\circ} \mathrm{C}$ for $12 \mathrm{~h}$. After conversion to $N, N$-dimethylvaline- $N$-oxide, the reaction mixture was analyzed by LCMS at a flow rate of $0.8 \mathrm{~mL} / \mathrm{min}$ on a DAICEL CHIRALPAK ID-3. Isocratic elution was performed using $85 \%$ solvent $\mathrm{A}\left(0.5 \%\right.$ acetic acid in $\left.\mathrm{H}_{2} \mathrm{O}\right)$ and $15 \%$ solvent $\mathrm{B}(0.45 \%$ acetic acid in $\mathrm{MeCN}$ ) for $55 \mathrm{~min}$.

Retention time (min): $42.2\left(\mathrm{~m} / z 358[\mathrm{M}+\mathrm{H}]^{+}, p\right.$-bromophenacyl ester of $N, N$-dimethyl L-valine- $N$-oxide), 43.0 ( $p$-bromophenacyl ester of $N, N$-dimethyl-D-valine- $N$-oxide), and the hydrolysate from 1 (42.2).

\section{Cytotoxicity Assay}

HeLa cells were cultured in Dulbecco's modified Eagle's medium containing penicillin and streptomycin and $10 \%$ fetal bovine serum at $37{ }^{\circ} \mathrm{C}$ under an atmosphere of $5 \% \mathrm{CO}_{2}$, and the cells were seeded in 96-well microplate containing $200 \mu \mathrm{L}$ of HeLa cell suspension. After overnight pre-incubation, compound 1 was added in quintuplicate at a starting concentration of $9.25 \mu \mathrm{M}$ and serial diluted to give concentrations of 1.85 , $0.37,0.074$, and $0.0148 \mu \mathrm{M}$. The cells were incubated for an additional $72 \mathrm{~h}$ before the 
addition of the MTT reagent. The supernatant was discarded, and the formazan dye was dissolved in $150 \mu \mathrm{L}$ of DMSO to be quantitated. A prarallel analysis using etoposide as a positive control gave an $\mathrm{IC}_{50}$ value of $0.5 \mu \mathrm{M}$.

1. Nübel, U.; Garcia-Pichel, F.; Muyzer, G. Appl. Environ. Microbiol. 1997, 63, 3327-3332. 2. Xiang, F.; Ye, H.; Chen, R.; Fu, Q; Li, L. Anal. Chem. 2010, 82, 2817-2825. 
Table S1. NMR Data for conformer A of heptavalinamide $\mathrm{A}(\mathbf{1})$ in $\mathrm{CD}_{3} \mathrm{OH}$.

\begin{tabular}{|c|c|c|c|c|c|}
\hline \multirow[b]{2}{*}{ position } & \multicolumn{2}{|c|}{ conformer A } & \multirow[b]{2}{*}{ TOCSY } & \multirow[b]{2}{*}{ HMBC } & \multirow[b]{2}{*}{ ROSEY (selected) } \\
\hline & $\delta_{\mathrm{C}}$, type $^{\mathrm{a}}$ & $\delta_{\mathrm{H}}$, mult $(J$ in $\mathrm{Hz})$ & & & \\
\hline$\overline{\mathrm{NMe}_{2} \text { Val-1 }}$ & & & & & \\
\hline 1 & 168.7, C & & & & \\
\hline 2 & $70.1, \mathrm{CH}$ & $4.51, \mathrm{~d}(5.0)$ & $3,4,5$ & $1,2,4,5$ & $\mathrm{NMe}, \mathrm{NMe}(\mathrm{NMeVal}-2)$ \\
\hline 3 & $29.7, \mathrm{CH}$ & $2.49, \mathrm{~m}$ & $2,4,5$ & 4,5 & \\
\hline 4 & $16.9, \mathrm{CH}_{3}$ & $1.03, \mathrm{~d}(6.7)$ & 2,3 & $2,3,5$ & $\mathrm{NMe}(\mathrm{NMeVal}-2)$ \\
\hline 5 & $19.1, \mathrm{CH}_{3}$ & $1.05, \mathrm{~d}(7.0)$ & 2,3 & $2,3,4$ & $\mathrm{NMe}(\mathrm{NMeVal}-2), 5$ (Pro-3) \\
\hline $\mathrm{NMe}$ & $42.6,{ }^{\mathrm{b}} \mathrm{CH}_{3}$ & $2.90, \mathrm{~s}$ & & 2, $\mathrm{NMe}$ & $4,5,4(\mathrm{NMeVal}-2)$ \\
\hline \multicolumn{6}{|l|}{ NMeVal-2 } \\
\hline 1 & 169.3, C & & & & \\
\hline 2 & $61.1, \mathrm{CH}$ & $5.18^{\mathrm{c}}$ & $3,4,5$ & 3, $\mathrm{NMe}$ & $\mathrm{NMe}(\mathrm{NMeVal}-1), \mathrm{NMe}, 5$ (Pro-3) \\
\hline 3 & $28.3, \mathrm{CH}$ & $2.33^{\mathrm{c}}$ & $2,4,5$ & 2 & \\
\hline 4 & $19.1, \mathrm{CH}_{3}$ & $0.89^{\mathrm{c}}$ & $2,3,5$ & 2,3 & $\mathrm{NMe}\left(\mathrm{NMe}_{2} \mathrm{Val}-1\right), \mathrm{NMe}$ \\
\hline 5 & $19.0, \mathrm{CH}_{3}$ & $1.01, \mathrm{~d}(6.7)$ & $2,3,4$ & $2,3,4$ & 5 (Pro-3) \\
\hline $\mathrm{NMe}$ & $31.9, \mathrm{CH}_{3}$ & $3.14, \mathrm{~s}$ & & $1\left(\mathrm{NMe}_{2} \mathrm{Val}-1\right), 2$ & $2\left(\mathrm{NMe}_{2} \mathrm{Val}-1\right), 5\left(\mathrm{NMe}_{2} \mathrm{Val}-1\right), 4$ \\
\hline $\begin{array}{l}\text { Pro-3 } \\
1\end{array}$ & $174.4, \mathrm{C}$ & & & & \\
\hline 2 & $58.4, \mathrm{CH}$ & $4.81^{\mathrm{d}}$ & & & \\
\hline 3 & $29.9, \mathrm{CH}_{2}$ & $1.74, \mathrm{~m}, 2.27, \mathrm{~m}$ & 4,5 & $1,2,4,5$ & $\mathrm{NMe}(\mathrm{NMeVal}-4)$ \\
\hline 4 & $25.7, \mathrm{CH}_{2}$ & $1.88, \mathrm{~m}, 2.09, \mathrm{~m}$ & 3,5 & $2,3,5$ & \\
\hline 5 & $49.1, \mathrm{CH}_{2}$ & $3.73, \mathrm{~m}, 3.97, \mathrm{~m}$ & 3,4 & 3,4 & 2(NMeVal-2), 5(NMeVal-2) \\
\hline \multicolumn{6}{|l|}{ NMeVal-4 } \\
\hline 1 & 172.2, C & & & & \\
\hline 2 & $59.9, \mathrm{CH}$ & $5.11, \mathrm{~d}(11.7)$ & $3,4,5$ & 1(Pro-3), 1, 4, NMe & $\mathrm{NMe}(\mathrm{NMeVal}-5)$ \\
\hline 3 & $28.2, \mathrm{CH}$ & $2.33^{\mathrm{c}}$ & $2,4,5$ & & \\
\hline 4 & $18.7, \mathrm{CH}_{3}$ & $0.90^{\mathrm{c}}$ & $2,3,5$ & $2,3,5$ & $\mathrm{NMe}$ \\
\hline 5 & $20.0, \mathrm{CH}_{3}$ & $0.88^{c}$ & 2,3 & 2 & \\
\hline $\mathrm{NMe}$ & $30.7, \mathrm{CH}_{3}$ & $3.08, \mathrm{~s}$ & & 1(Pro-3), 2 & 2(Pro-3), 3(Pro-3), 4, 4(NMeVal-5) \\
\hline \multicolumn{6}{|l|}{ NMeVal-5 } \\
\hline 1 & $171.8, \mathrm{C}$ & & & & \\
\hline 2 & $59.7, \mathrm{CH}$ & $5.18^{\mathrm{c}}$ & $3,4,5$ & $3,4, \mathrm{NMe}$ & $\mathrm{NMe}(\mathrm{NMeVal}-6)$ \\
\hline 3 & $28.2, \mathrm{CH}$ & $2.33^{\mathrm{c}}$ & $2,4,5$ & & \\
\hline 4 & $18.2, \mathrm{CH}_{3}$ & $0.76, \mathrm{~d}$ & $2,3,5$ & $2,3,5$ & $\mathrm{NMe}(\mathrm{NMeVal}-4), \mathrm{NMe}$ \\
\hline 5 & $19.8, \mathrm{CH}_{3}$ & $0.87^{\mathrm{c}}$ & $2,3,4$ & 2,3 & $\mathrm{NMe}(\mathrm{NMeVal-7)}$ \\
\hline $\mathrm{NMe}$ & $30.8, \mathrm{CH}_{3}$ & $2.98, \mathrm{~s}$ & & 1(NMeVal-4), 2 & 3(Pro-3), 2(NMeVal-4), 5(NMeVal-4), 4, 4(NMeVal-6) \\
\hline \multicolumn{6}{|l|}{ NMeVal-6 } \\
\hline 1 & 171.6, C & & & & \\
\hline 2 & $59.7, \mathrm{CH}$ & $5.14, \mathrm{~d}(11.6)$ & $3,4,5$ & $3, \mathrm{NMe}$ & $\mathrm{NMe}(\mathrm{NMeVal-7)}$ \\
\hline 3 & $28.2, \mathrm{CH}$ & $2.31^{\mathrm{c}}$ & $2,4,5$ & & \\
\hline 4 & $18.2, \mathrm{CH}_{3}$ & $0.74^{\mathrm{c}}$ & $2,3,5$ & 2,3 & $\mathrm{NMe}(\mathrm{NMeVal}-5)$ \\
\hline 5 & $19.7, \mathrm{CH}_{3}$ & $0.83, \mathrm{~d}(6.3)$ & $2,3,5$ & $2,3,4$ & $\mathrm{NMe}(\mathrm{NMeVal}-8)$ \\
\hline $\mathrm{NMe}$ & $30.9, \mathrm{CH}_{3}$ & $3.02,{ }^{\mathrm{e}} \mathrm{s}$ & & 1(NMeVal-5), 2 & 5(NMeVal-4), 2(NMeVal-5), 4(NMeVal-7) \\
\hline \multicolumn{6}{|l|}{ NMeVal-7 } \\
\hline 1 & 171.1, C & & & & \\
\hline 2 & $59.6, \mathrm{CH}$ & 4.97, d (11.5) & $3,4,5$ & $3,5, \mathrm{NMe}$ & $\mathrm{NMe}(\mathrm{NMeVal}-8)$ \\
\hline 3 & $28.3, \mathrm{CH}$ & $2.25, \mathrm{~m}$ & $2,4,5$ & & \\
\hline 4 & $18.1, \mathrm{CH}_{3}$ & $0.74^{\mathrm{c}}$ & $2,3,5$ & $2,3,5$ & $\mathrm{NMe}(\mathrm{NMeVal}-6), \mathrm{NMe}$ \\
\hline 5 & $20.1, \mathrm{CH}_{3}$ & $0.79, \mathrm{~d}(6.7)$ & $2,3,4$ & 3,4 & NMe(NMePhe-9), 5(NMePhe-9) \\
\hline $\mathrm{NMe}$ & $31.1, \mathrm{CH}_{3}$ & $2.97, \mathrm{~s}$ & & 1(NMeVal-6), 2 & 5(NMeVal-5), 2(NMeVal-6), 4, 4(NMeVal-8) \\
\hline \multicolumn{6}{|l|}{ NMeVal-8 } \\
\hline 1 & 171.6, C & & & & \\
\hline 2 & $59.7, \mathrm{CH}$ & $5.03, \mathrm{~d}(10.8)$ & $3,4,5$ & $3,5, \mathrm{NMe}$ & $\mathrm{NMe}(\mathrm{NMePhe}-9)$ \\
\hline 3 & $28.0, \mathrm{CH}$ & $2.20, \mathrm{~m}$ & $2,4,5$ & 2 & \\
\hline 4 & $17.9, \mathrm{CH}_{3}$ & $0.67, \mathrm{~d}(7.0)$ & $2,3,5$ & $2,3,5$ & $\mathrm{NMe}(\mathrm{NMeVal}-7), \mathrm{NMe}$ \\
\hline 5 & $20.0, \mathrm{CH}_{3}$ & $0.89, \mathrm{~d}$ & $2,3,4$ & 3,4 & $5 / 9(\mathrm{NMePhe}-9)$ \\
\hline $\mathrm{NMe}$ & $30.4, \mathrm{CH}_{3}$ & $2.43, \mathrm{~s}$ & & 1(NMeVal-7), 2 & 5(NMeVal-6), 2(NMeVal-7), 4 \\
\hline \multicolumn{6}{|l|}{ NMePhe-9 } \\
\hline 1 & $173,4,{ }^{\mathrm{f}} \mathrm{C}$ & & & & \\
\hline 2 & $59.7, \mathrm{CH}$ & 5.35 , broad & 3 & & 3 \\
\hline 3 & $35.1, \mathrm{CH}_{2}$ & $3.09^{\mathrm{c}}, 3.39, \mathrm{~m}$ & 2 & $4,5 / 9$ & $2,5 / 9$ \\
\hline 4 & $138.8, \mathrm{C}$ & & & & \\
\hline $5 / 9$ & $129.9, \mathrm{CH}$ & $7.20^{\mathrm{c}}$ & 7 & 3,7 & 5(NMeVal-7), 5(NMeVal-8), NMe \\
\hline $6 / 8$ & $129.5, \mathrm{CH}$ & $7.28, \mathrm{~m}$ & 7 & 4 & \\
\hline 7 & $127.8, \mathrm{C}$ & $7.25, \mathrm{~m}$ & $5 / 9$ & $5 / 9$ & \\
\hline $\mathrm{NMe}$ & $30.7, \mathrm{CH}_{3}$ & $2.87, \mathrm{~s}$ & & 1(NMeVal-8), 2 & 5(NMeVal-7), 2(NMeVal-8) \\
\hline
\end{tabular}

a Assigned by HSQC and HMBC data. The signal for acetic acid $\left(\mathrm{d}_{\mathrm{H}} 1.98 ; \mathrm{d}_{\mathrm{C}} 175.2\right.$ and 20.6), which was used during the last step of HPLC purification, was observed.

${ }^{\mathrm{b}}$ Did not give a distinct signal in the ${ }^{13} \mathrm{C}$ NMR spectrum. The chemical shift was assigned on the basis of HSQC and HMBC spectra.

c Overlapping precluded the determination of multiplicity.

${ }^{\mathrm{d}}$ Overlapped with water. ${ }^{\mathrm{e}}$ Assignments may be interchanged. ${ }^{\mathrm{f}}$ Tentatively assigned due to the lack of correlation to ${ }^{1} \mathrm{H}$ signals. 
Table S2. NMR Data for conformer B of heptavalinamide $\mathrm{A}(\mathbf{1})$ in $\mathrm{CD}_{3} \mathrm{OH}$.

\begin{tabular}{|c|c|c|c|c|c|}
\hline \multirow[b]{2}{*}{ position } & \multicolumn{2}{|c|}{ conformer B } & \multirow[b]{2}{*}{ TOCSY } & \multirow[b]{2}{*}{ HMBC } & \multirow[b]{2}{*}{ ROSEY (selected) } \\
\hline & $\delta_{\mathrm{C}}$, type $^{\mathrm{a}}$ & $\delta_{\mathrm{H}}$, mult $(J$ in $\mathrm{Hz})$ & & & \\
\hline \multicolumn{6}{|l|}{$\mathrm{NMe}_{2}$ Val-1 } \\
\hline 1 & 168.7, C & & & & \\
\hline 2 & $70.1, \mathrm{CH}$ & $4.51, \mathrm{~d}(5.0)$ & $3,4,5$ & $1,2,4,5$ & $\mathrm{NMe}, \mathrm{NMe}(\mathrm{NMeVal}-2)$ \\
\hline 3 & $29.7, \mathrm{CH}$ & $2.49, \mathrm{~m}$ & $2,4,5$ & 4,5 & \\
\hline 4 & $16.9, \mathrm{CH}_{3}$ & $1.03, \mathrm{~d}(6.7)$ & 2,3 & $2,3,5$ & $\mathrm{NMe}(\mathrm{NMeVal}-2)$ \\
\hline 5 & $19.1, \mathrm{CH}_{3}$ & $1.05, \mathrm{~d}(7.0)$ & 2,3 & $2,3,4$ & $\mathrm{NMe}(\mathrm{NMeVal}-2), 5$ (Pro-3) \\
\hline $\mathrm{NMe}$ & $42.6,{ }^{\mathrm{b}} \mathrm{CH}_{3}$ & $2.90, \mathrm{~s}$ & & 2, $\mathrm{NMe}$ & $4,5,4(\mathrm{NMeVal}-2)$ \\
\hline \multicolumn{6}{|l|}{ NMeVal-2 } \\
\hline 1 & $169.3, \mathrm{C}$ & & & & \\
\hline 2 & $61.1, \mathrm{CH}$ & $5.18^{\mathrm{c}}$ & $3,4,5$ & $3, \mathrm{NMe}$ & $\mathrm{NMe}(\mathrm{NMeVal}-1), \mathrm{NMe}, 5$ (Pro-3) \\
\hline 3 & $28.3, \mathrm{CH}$ & $2.33^{\mathrm{c}}$ & $2,4,5$ & 2 & \\
\hline 4 & $19.1, \mathrm{CH}_{3}$ & $0.89^{\mathrm{c}}$ & $2,3,5$ & 2,3 & $\mathrm{NMe}\left(\mathrm{NMe}_{2}\right.$ Val-1), $\mathrm{NMe}$ \\
\hline 5 & $19.0, \mathrm{CH}_{3}$ & $1.01, \mathrm{~d}(6.7)$ & $2,3,4$ & $2,3,4$ & 5 (Pro-3) \\
\hline $\mathrm{NMe}$ & $31.9, \mathrm{CH}_{3}$ & $3.14, \mathrm{~s}$ & & $1\left(\mathrm{NMe}_{2} \mathrm{Val}-1\right), 2$, & $2\left(\mathrm{NMe}_{2}\right.$ Val-1), $5\left(\mathrm{NMe}_{2}\right.$ Val-1), 4 \\
\hline $\begin{array}{l}\text { Pro-3 } \\
1\end{array}$ & 174.4, C & & & & \\
\hline 2 & $58.4, \mathrm{CH}$ & $4.81^{\mathrm{d}}$ & & & \\
\hline 3 & $29.9, \mathrm{CH}_{2}$ & $1.74, \mathrm{~m}, 2.27, \mathrm{~m}$ & 4,5 & $1,2,4,5$ & $\mathrm{NMe}(\mathrm{NMeVal}-4)$ \\
\hline 4 & $25.7, \mathrm{CH}_{2}$ & $1.88, \mathrm{~m}, 2.09, \mathrm{~m}$ & 3,5 & $2,3,5$ & \\
\hline 5 & $49.1, \mathrm{CH}_{2}$ & $3.73, \mathrm{~m}, 3.97, \mathrm{~m}$ & 3,4 & 3,4 & 2(NMeVal-2), 5(NMeVal-2) \\
\hline \multicolumn{6}{|l|}{ NMeVal-4 } \\
\hline 1 & $172.2, \mathrm{C}$ & & & & \\
\hline 2 & $59.9, \mathrm{CH}$ & $5.11, \mathrm{~d}(11.7)$ & $3,4,5$ & 1(Pro-3), 1, 4, NMe & $\mathrm{NMe}(\mathrm{NMeVal}-5)$ \\
\hline 3 & $28.2, \mathrm{CH}$ & $2.33^{\mathrm{c}}$ & $2,4,5$ & & \\
\hline 4 & $18.7, \mathrm{CH}_{3}$ & $0.90^{\mathrm{c}}$ & $2,3,5$ & $2,3,5$ & $\mathrm{NMe}$ \\
\hline 5 & $20.0, \mathrm{CH}_{3}$ & $0.88^{\mathrm{c}}$ & 2,3 & 2 & \\
\hline $\mathrm{NMe}$ & $30.7, \mathrm{CH}_{3}$ & $3.08, \mathrm{~s}$ & & 1(Pro-3), 2 & 2(Pro-3), 3(Pro-3), 4, 4(NMeVal-5) \\
\hline \multicolumn{6}{|l|}{ NMeVal-5 } \\
\hline 1 & $171.8, \mathrm{C}$ & & & & \\
\hline 2 & $59.7, \mathrm{CH}$ & $5.18^{\mathrm{c}}$ & $3,4,5$ & $3,4, \mathrm{NMe}$ & NMe(NMeVal-6) \\
\hline 3 & $28.2, \mathrm{CH}$ & $2.33^{\mathrm{c}}$ & $2,4,5$ & & \\
\hline 4 & $18.2, \mathrm{CH}_{3}$ & $0.76, \mathrm{~d}$ & $2,3,5$ & $2,3,5$ & $\mathrm{NMe}(\mathrm{NMeVal}-4), \mathrm{NMe}$ \\
\hline 5 & $19.8, \mathrm{CH}_{3}$ & $0.87^{\mathrm{c}}$ & $2,3,4$ & 2,3 & $\mathrm{NMe}(\mathrm{NMeVal-7)}$ \\
\hline $\mathrm{NMe}$ & $30.8, \mathrm{CH}_{3}$ & $2.98, \mathrm{~s}$ & & 1(NMeVal-4), 2 & 3(Pro-3), 2(NMeVal-4), 5(NMeVal-4), 4, 4(NMeVal-6) \\
\hline \multicolumn{6}{|l|}{ NMeVal-6 } \\
\hline 1 & $171.6, \mathrm{C}$ & & & & \\
\hline 2 & $59.7, \mathrm{CH}$ & $5.16, \mathrm{~d}(11.4)$ & $3,4,5$ & $5, \mathrm{NMe}$ & $\mathrm{NMe}(\mathrm{NMe}-\mathrm{Val}-7)$ \\
\hline 3 & $28.2, \mathrm{CH}$ & $2.31^{\mathrm{c}}$ & $2,4,5$ & & \\
\hline 4 & $18.2, \mathrm{CH}_{3}$ & $0.74, \mathrm{~d}(7.0)$ & $2,3,5$ & $2,3,5$ & $\mathrm{NMe}(\mathrm{NMeVal}-5)$ \\
\hline 5 & $19.7, \mathrm{CH}_{3}$ & $0.85^{\mathrm{c}}$ & $2,3,4$ & $2,3,4$ & $\mathrm{NMe}(\mathrm{NMeVal}-8)$ \\
\hline $\mathrm{NMe}$ & $30.9, \mathrm{CH}_{3}$ & $3.03,{ }^{\mathrm{e}} \mathrm{s}$ & & 1 (NMeVal-5), 2 & 5(NMeVal-4), 2(NMeVal-5), 4(NMeVal-7) \\
\hline \multicolumn{6}{|l|}{ NMeVal-7 } \\
\hline 1 & $170.9, \mathrm{C}$ & & & & \\
\hline 2 & $59.9, \mathrm{CH}$ & $5.10, \mathrm{~d}(10.3)$ & $3,4,5$ & $5, \mathrm{NMe}$ & $\mathrm{NMe}(\mathrm{NMeVal}-8)$ \\
\hline 3 & $28.3, \mathrm{CH}$ & $2.33^{\mathrm{c}}$ & $2,4,5$ & & \\
\hline 4 & $18.2, \mathrm{CH}_{3}$ & $0.74^{\mathrm{c}}$ & $2,3,5$ & 2,3 & $\mathrm{NMe}(\mathrm{NMeVal}-6), \mathrm{NMe}$ \\
\hline 5 & $19.9, \mathrm{CH}_{3}$ & $0.88, \mathrm{~d}$ & $2,3,4$ & $2,3,4$ & 2(NMePhe-9) \\
\hline $\mathrm{NMe}$ & $31.1, \mathrm{CH}_{3}$ & $2.96, \mathrm{~s}$ & & 1 (NMeVal-6), 2 & 2(NMeVal-6), 4, 4(NMeVal-8) \\
\hline \multicolumn{6}{|l|}{ NMeVal-8 } \\
\hline 1 & 171.6, C & & & & \\
\hline 2 & $59.7, \mathrm{CH}$ & $4.49, \mathrm{~d}(10.1)$ & $3,4,5$ & $1,3,5, \mathrm{NMe}$ & 2(NMePhe-9) \\
\hline 3 & $28.0, \mathrm{CH}$ & $2.06, \mathrm{~m}$ & $2,4,5$ & & \\
\hline 4 & $17.8, \mathrm{CH}_{3}$ & $0.53, \mathrm{~d}$ & $2,3,5$ & $2,3,5$ & $\mathrm{NMe}(\mathrm{NMeVal}-7), \mathrm{NMe}$ \\
\hline 5 & $19.3, \mathrm{CH}_{3}$ & $0.11, \mathrm{~d}(6.7)$ & $2,3,4$ & $2,3,4$ & 5 (NMePhe-9) \\
\hline $\mathrm{NMe}$ & $30.7, \mathrm{CH}_{3}$ & $2.81, \mathrm{~s}$ & & 1 (NMeVal-7), 2 & 5(NMeVal-6), 2(NMeVal-7), \\
\hline \multicolumn{6}{|l|}{ NMePhe-9 } \\
\hline 1 & $172.6, \mathrm{C}$ & & & & \\
\hline 2 & $62.4, \mathrm{CH}$ & 4.90 , broad & 3 & $\mathrm{NMe}$ & 5(NMeVal-7), 2(NMeVal-8) \\
\hline 3 & $35.7, \mathrm{CH}_{2}$ & $2.99^{\mathrm{c}}, 3.37, \mathrm{~m}$ & 2 & $2,4,5 / 9$ & $2,5 / 9$ \\
\hline 4 & $138.5, \mathrm{C}$ & & & & \\
\hline $5 / 9$ & $130.5, \mathrm{CH}$ & $7.31^{\mathrm{c}}$ & 7 & 7 & 2(NMe-Val-8), 5(NMeVal-8), 2, NMe \\
\hline $6 / 8$ & $129.8, \mathrm{CH}$ & $7.31^{\mathrm{c}}$ & 7 & $4,5 / 9$ & \\
\hline 7 & $127.9, \mathrm{CH}$ & $7.22, \mathrm{~m}$ & $5 / 9$ & $5 / 9$ & \\
\hline $\mathrm{NMe}$ & $30.7, \mathrm{CH}_{3}$ & $2.87, \mathrm{~s}$ & & 1(NMeVal-8), 2 & \\
\hline
\end{tabular}

a Assigned by HSQC and HMBC data. The signal for acetic acid $\left(\mathrm{d}_{\mathrm{H}} 1.98 ; \mathrm{d}_{\mathrm{C}} 175.2\right.$ and 20.6), which was used during the last step of HPLC purification, was observed.

${ }^{b}$ Did not give a distinct signal in the ${ }^{13} \mathrm{C}$ NMR spectrum. The chemical shift was assigned on the basis of HSQC and HMBC spectra.

${ }^{\mathrm{c}}$ Overlapping precluded the determination of multiplicity.

${ }^{\mathrm{d}}$ Overlapped with water. ${ }^{\mathrm{e}}$ Assignments may be interchanged. 


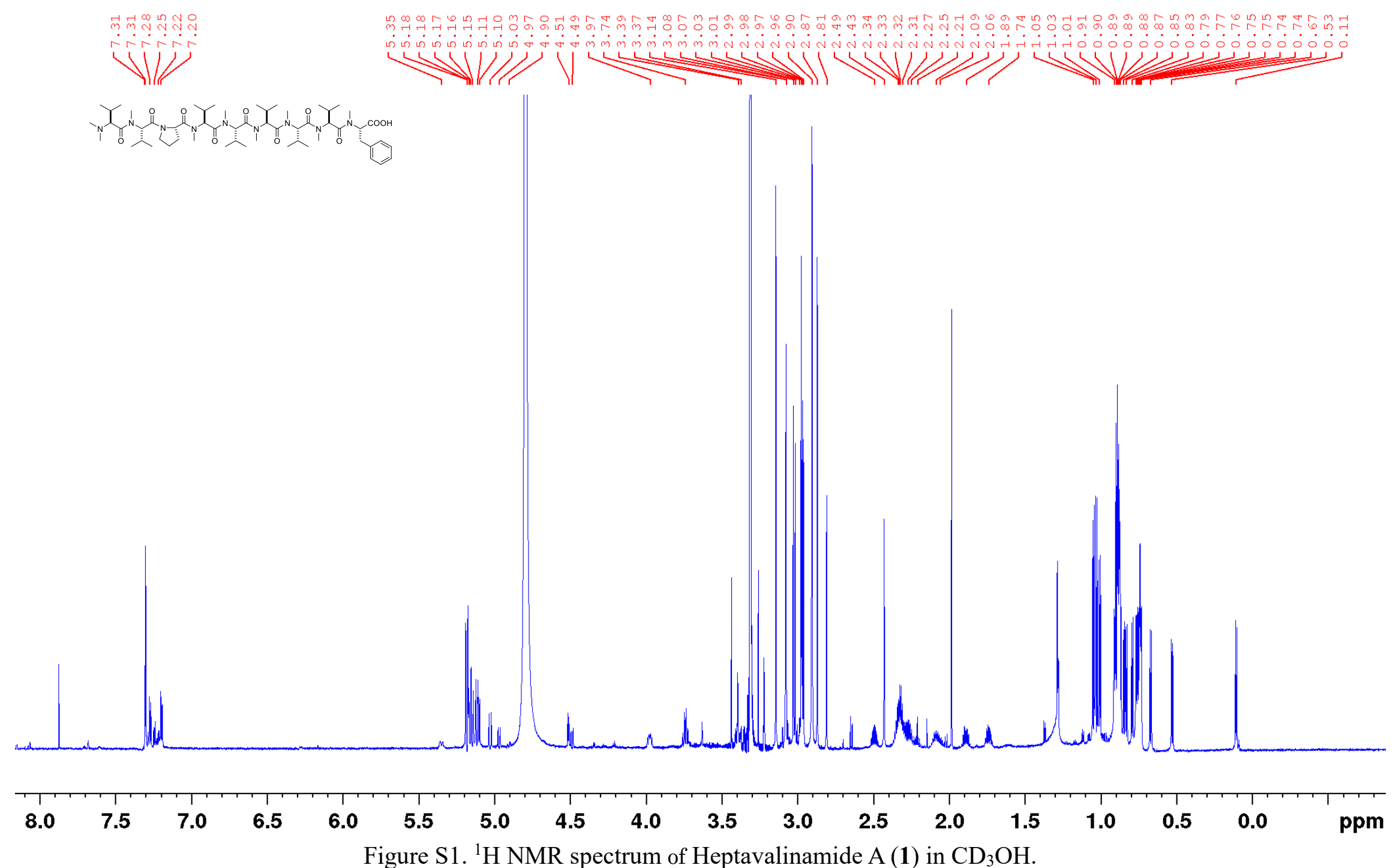




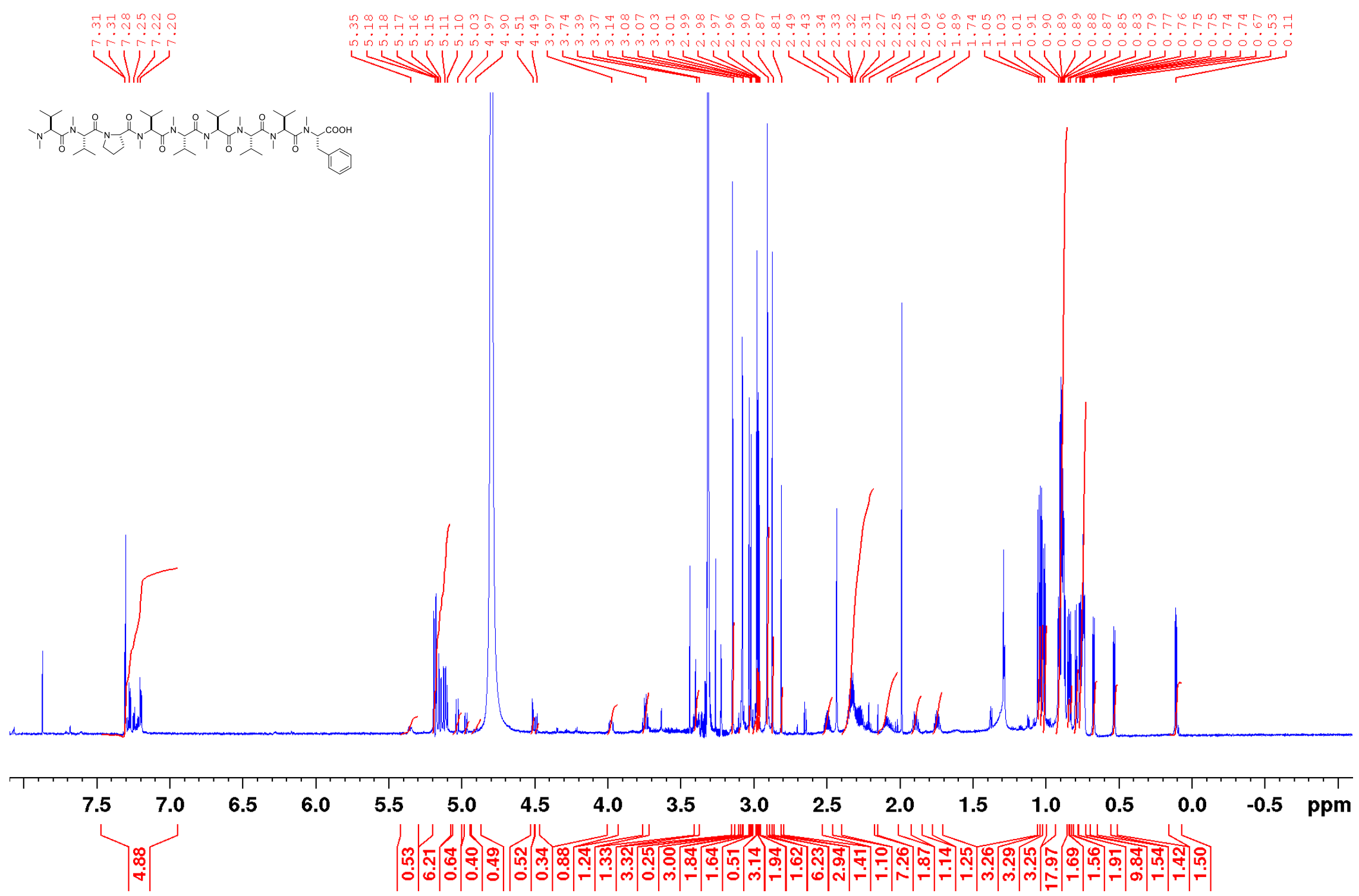

Figure S2. ${ }^{1} \mathrm{H}$ NMR spectrum of Heptavalinamide A (1) in $\mathrm{CD}_{3} \mathrm{OH}$. 


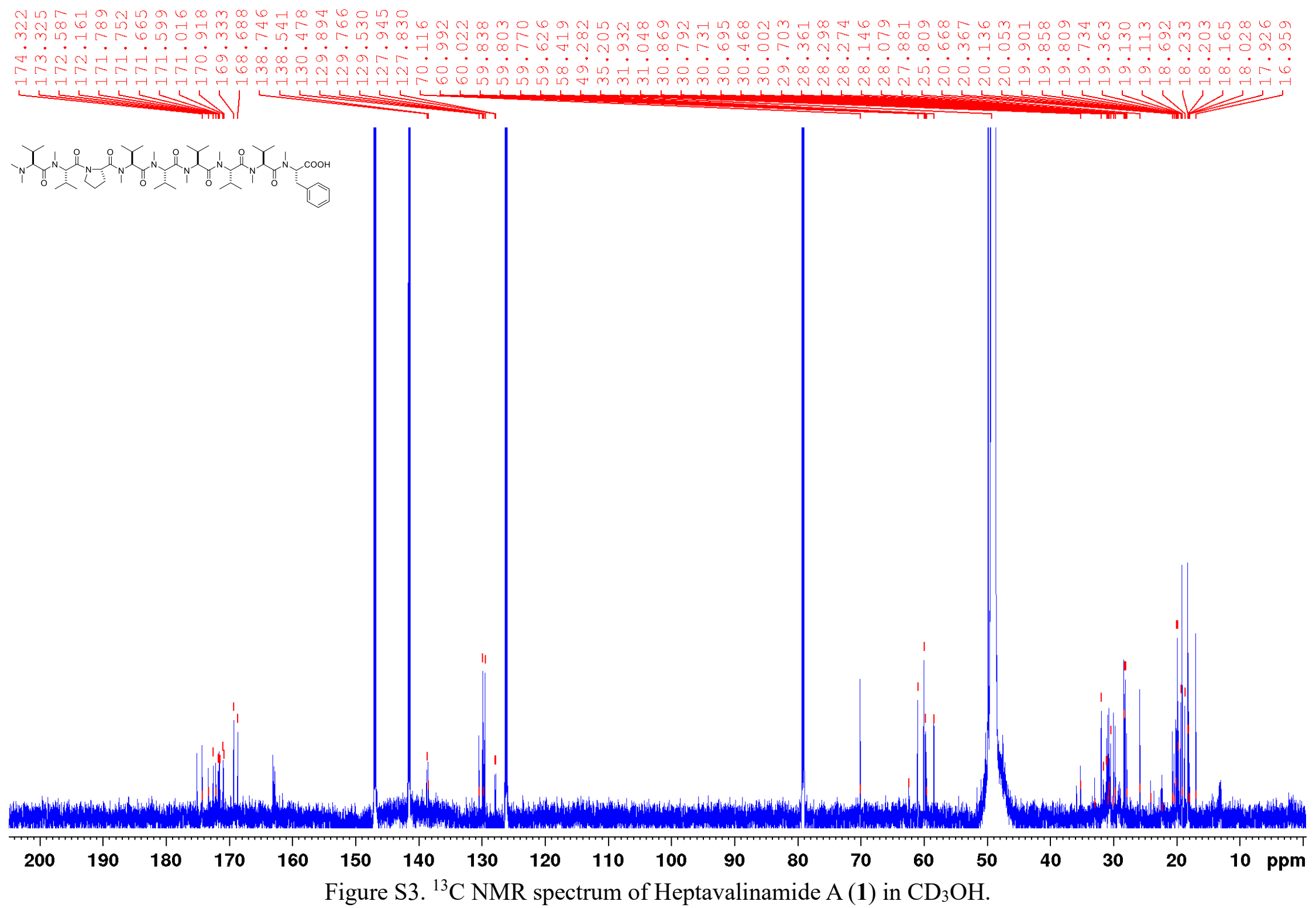

13 


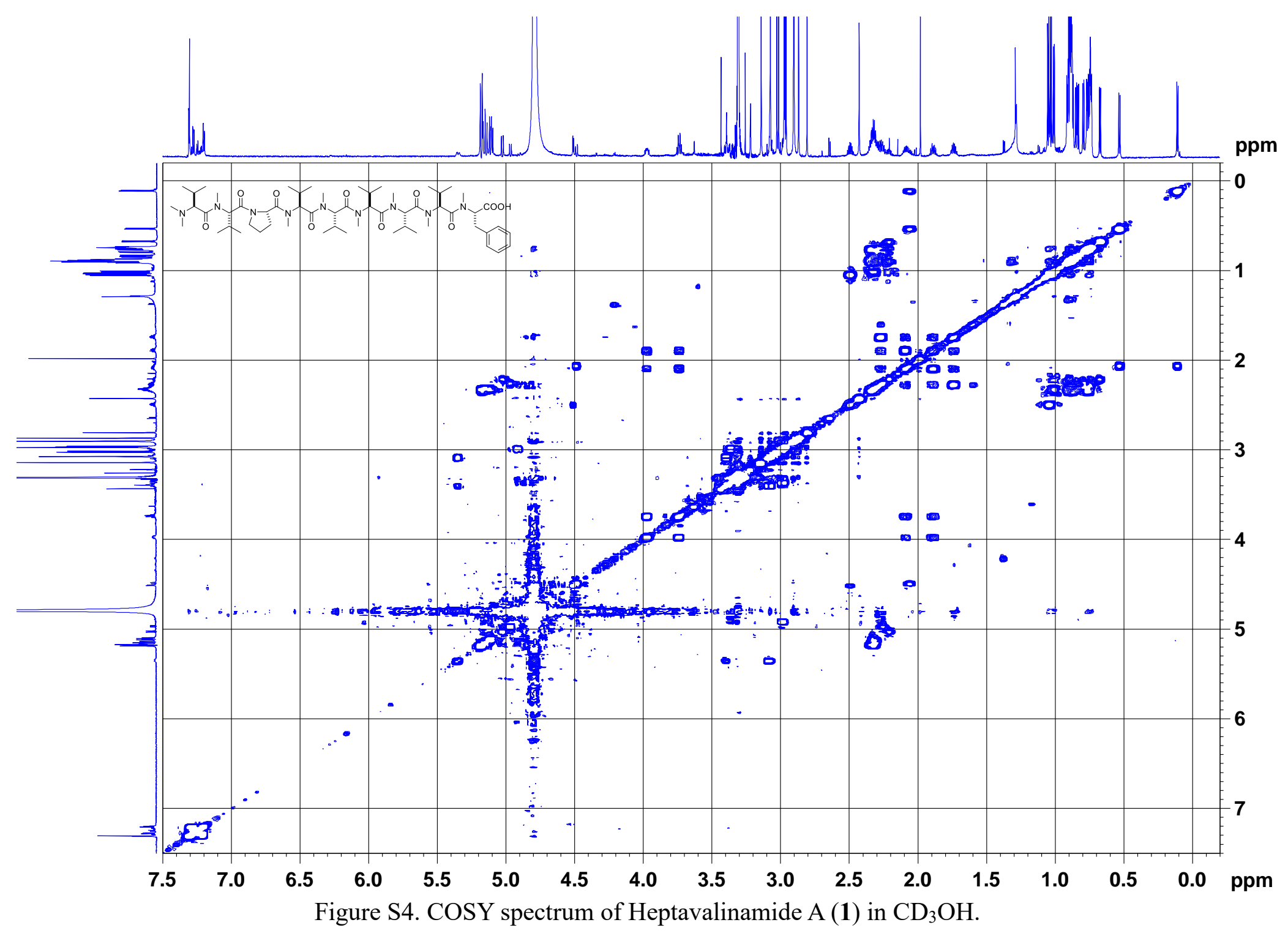




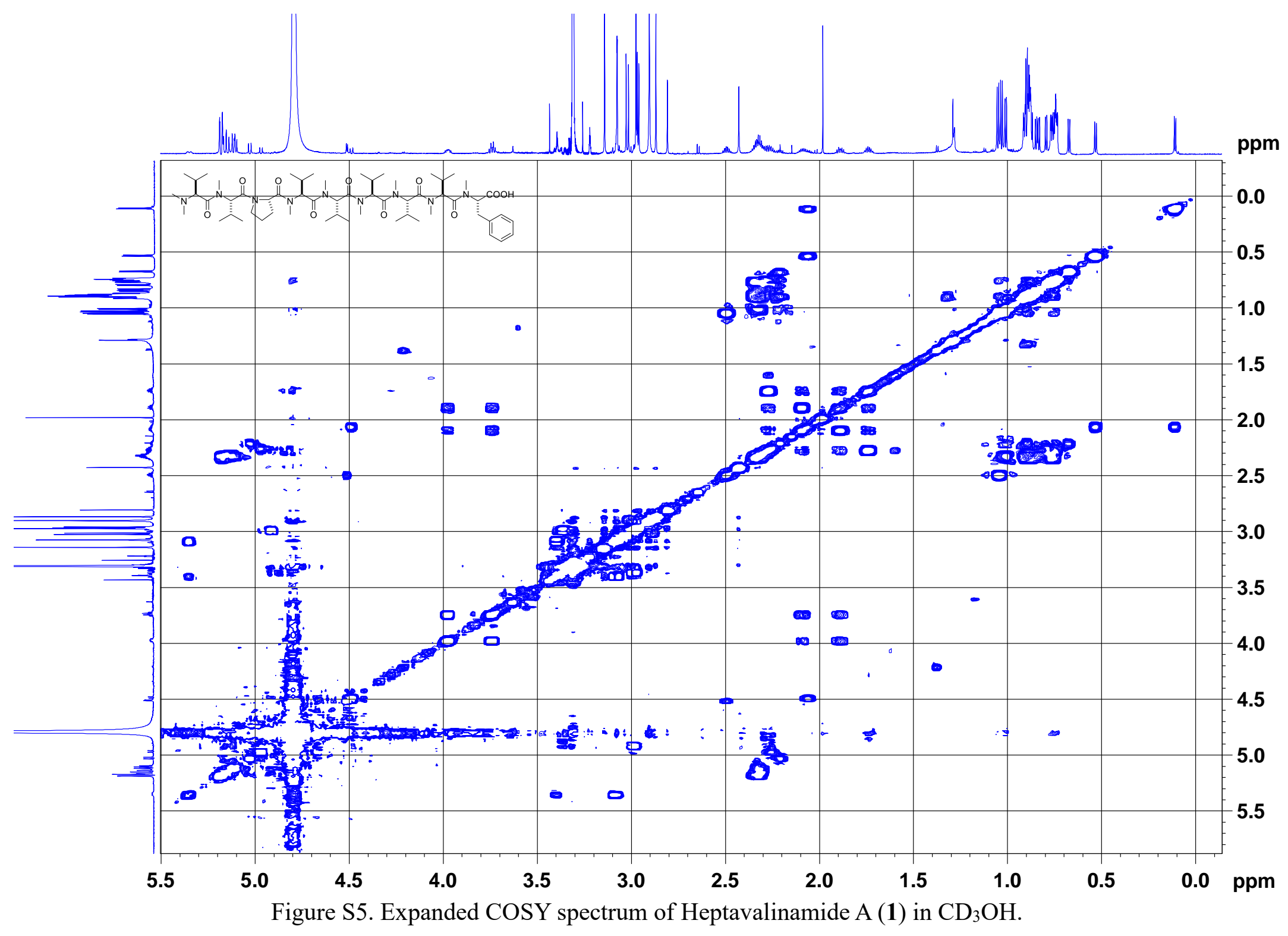




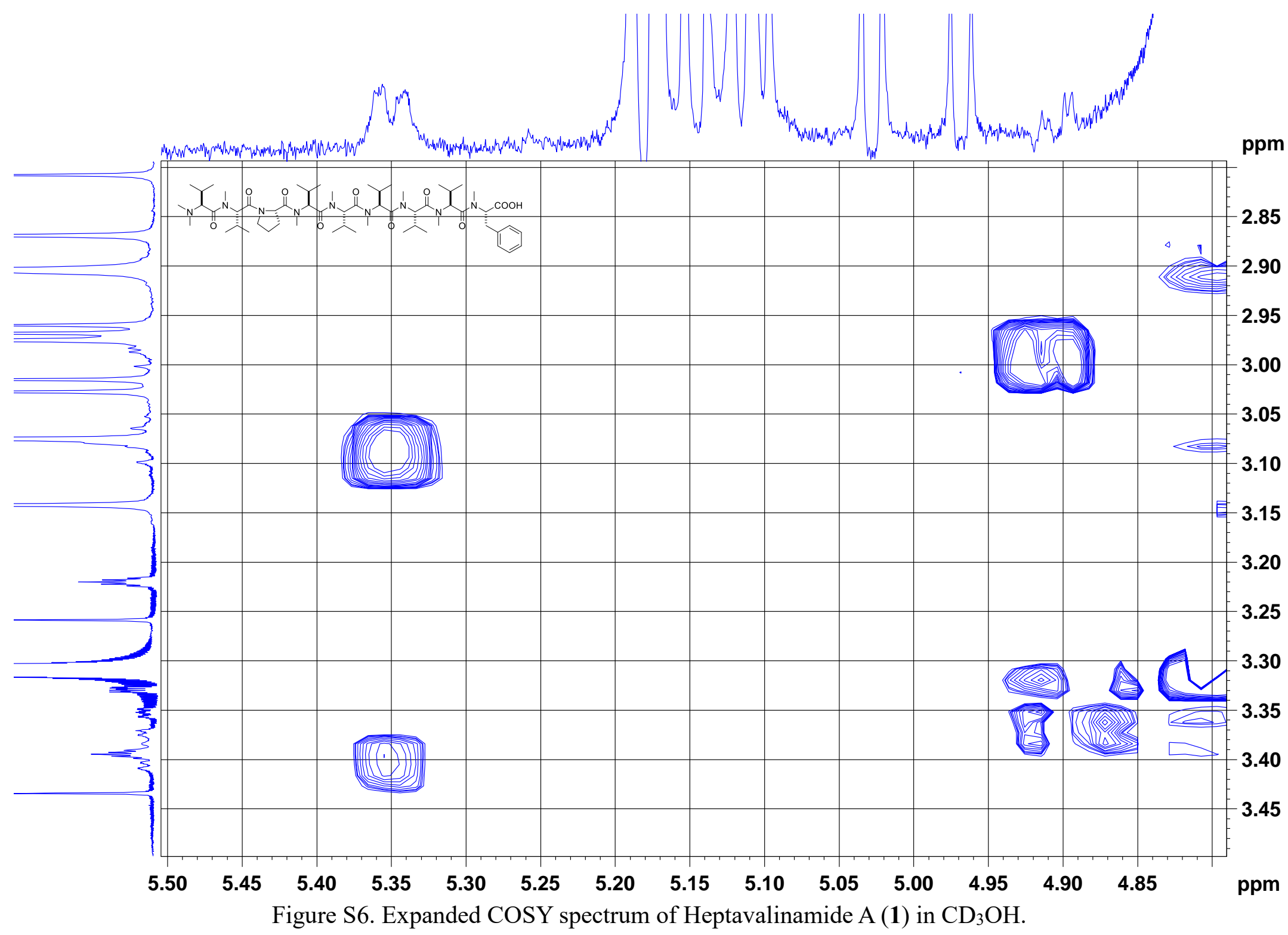




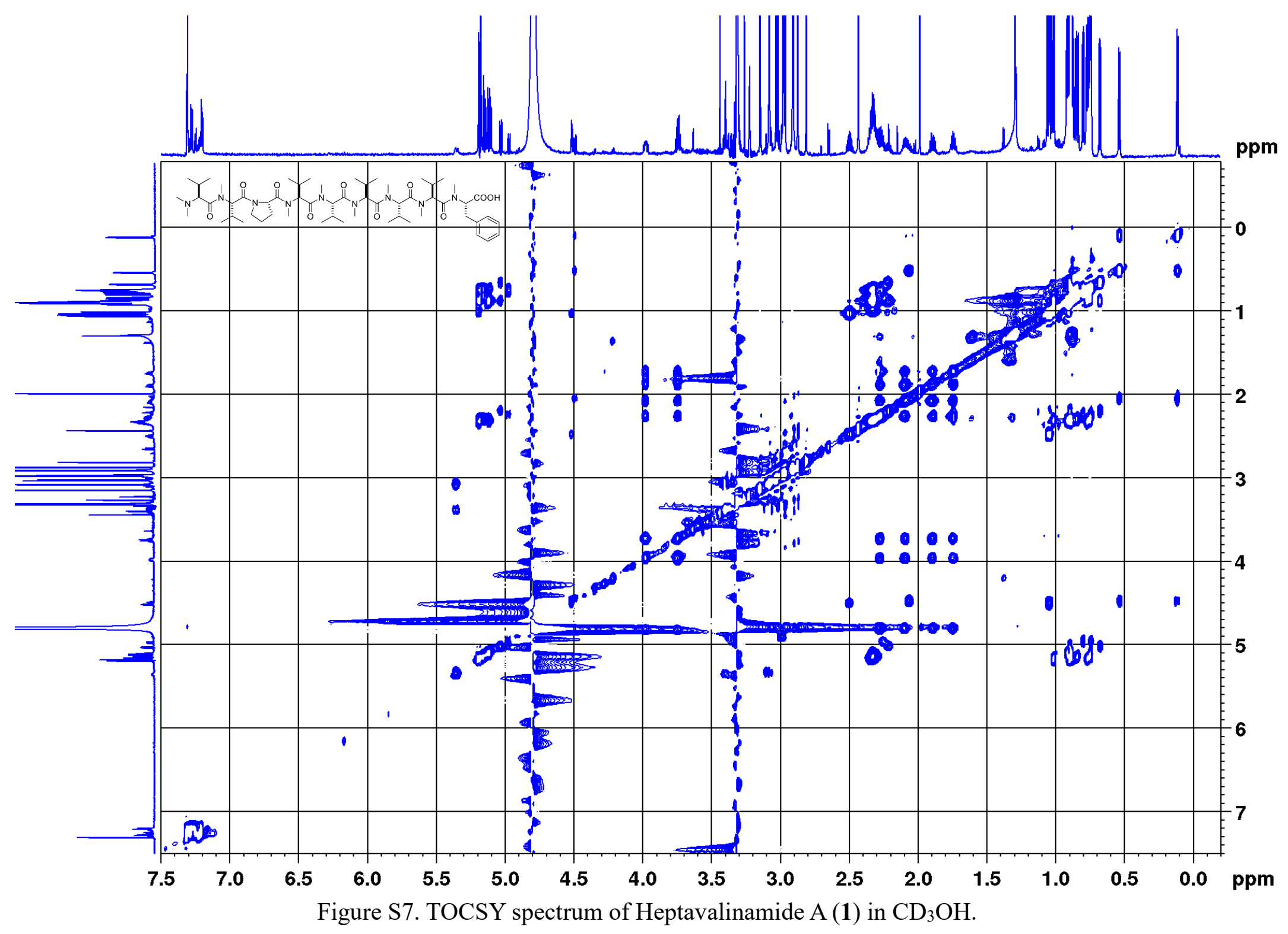




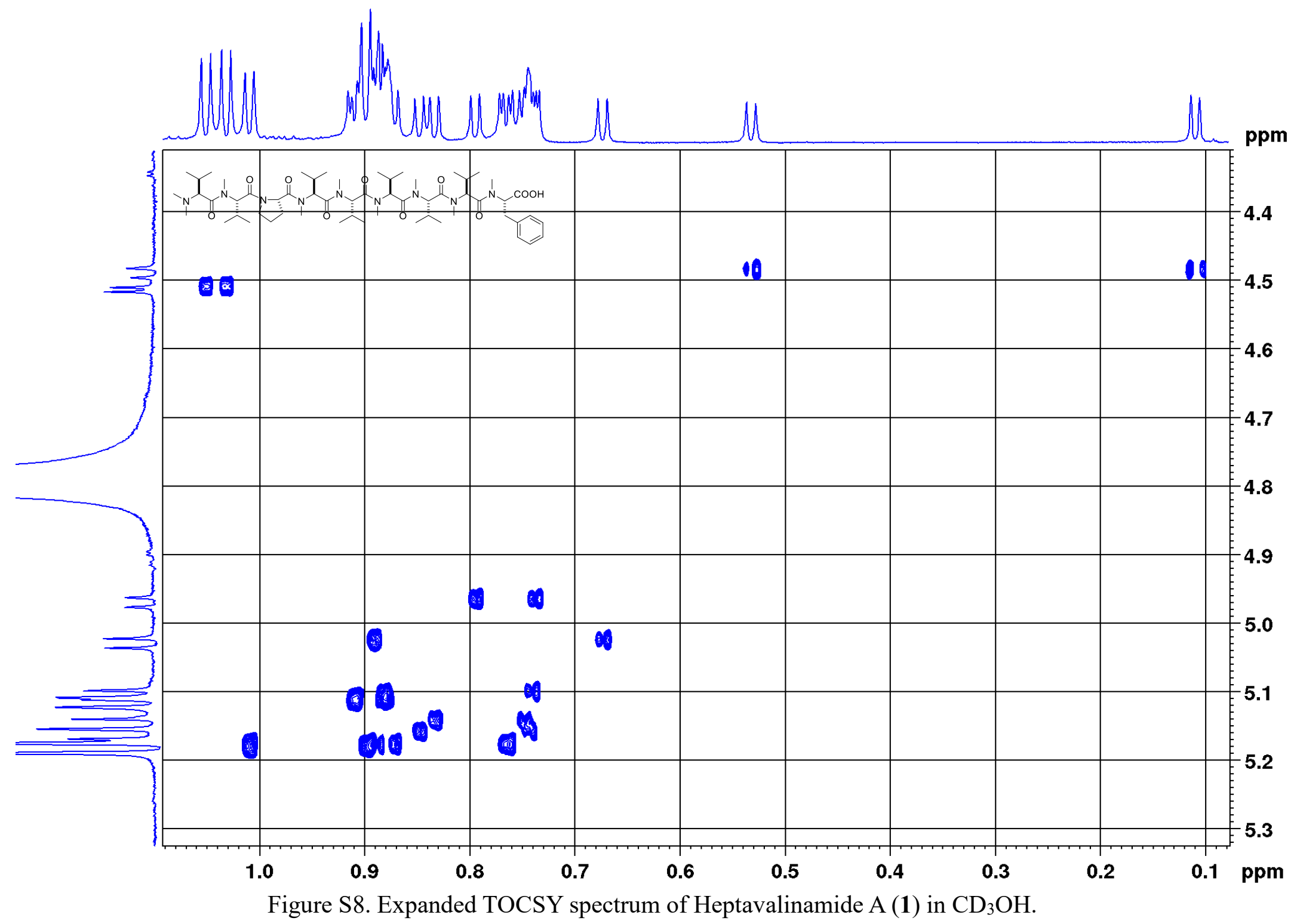




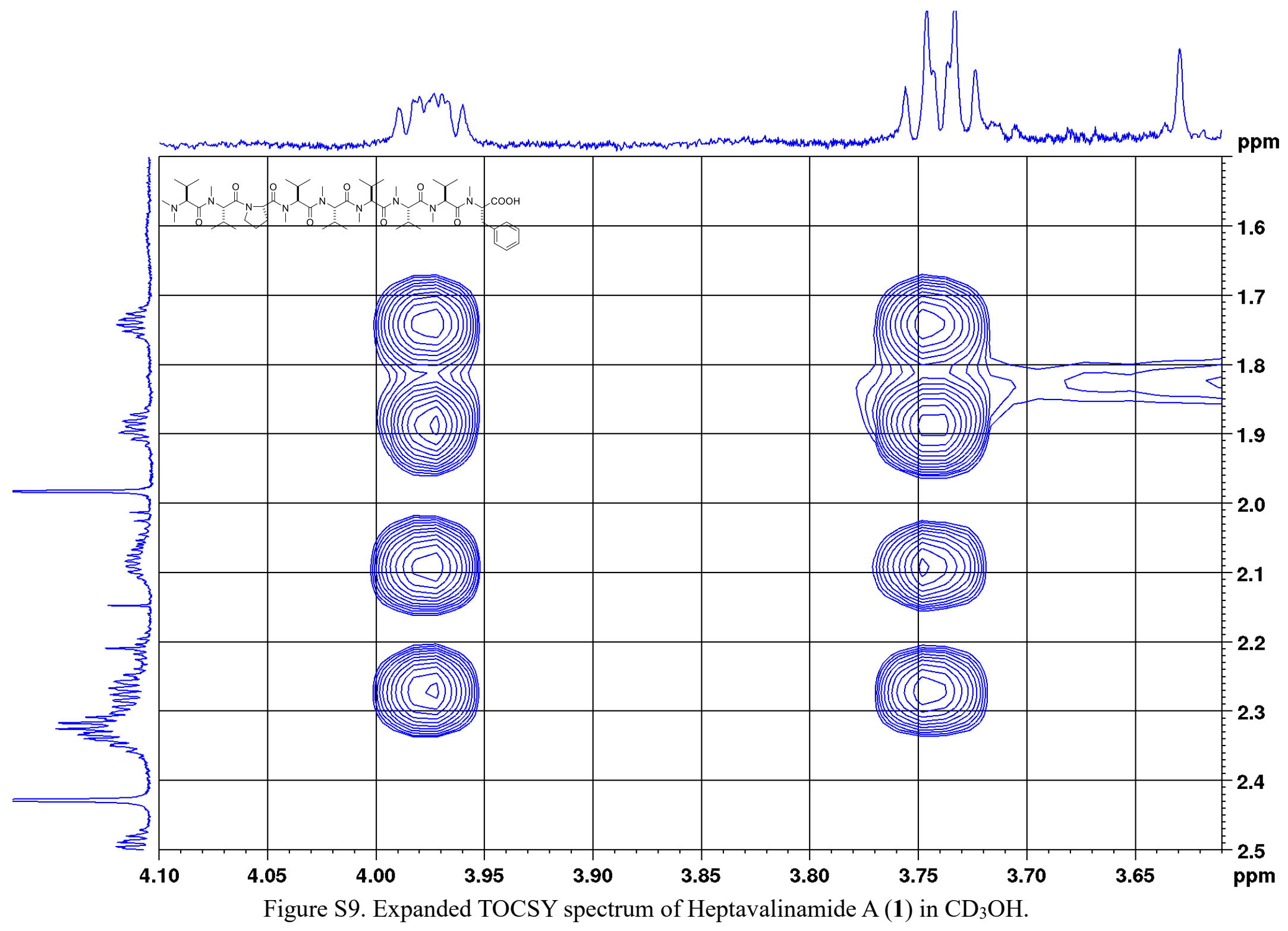




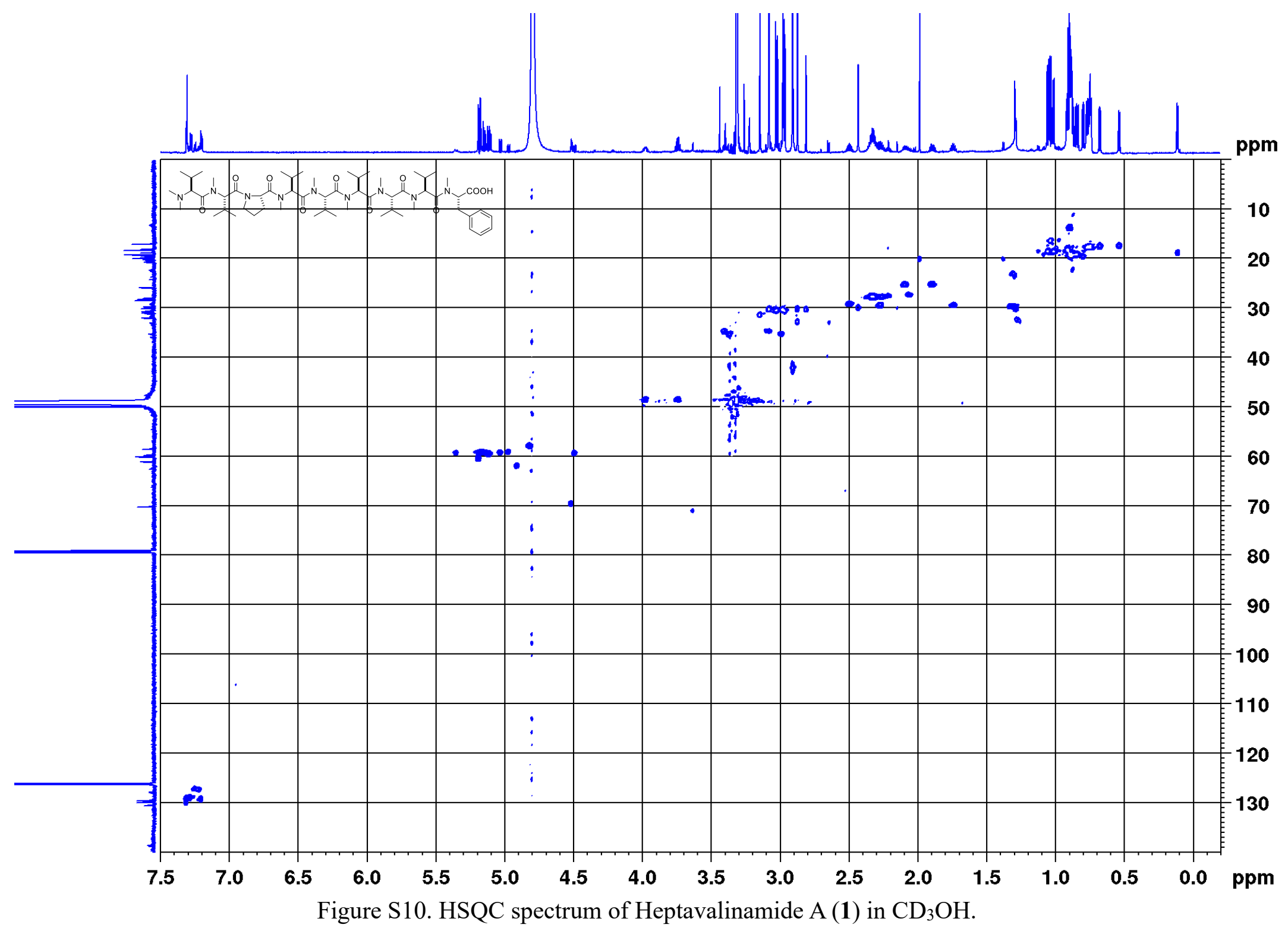




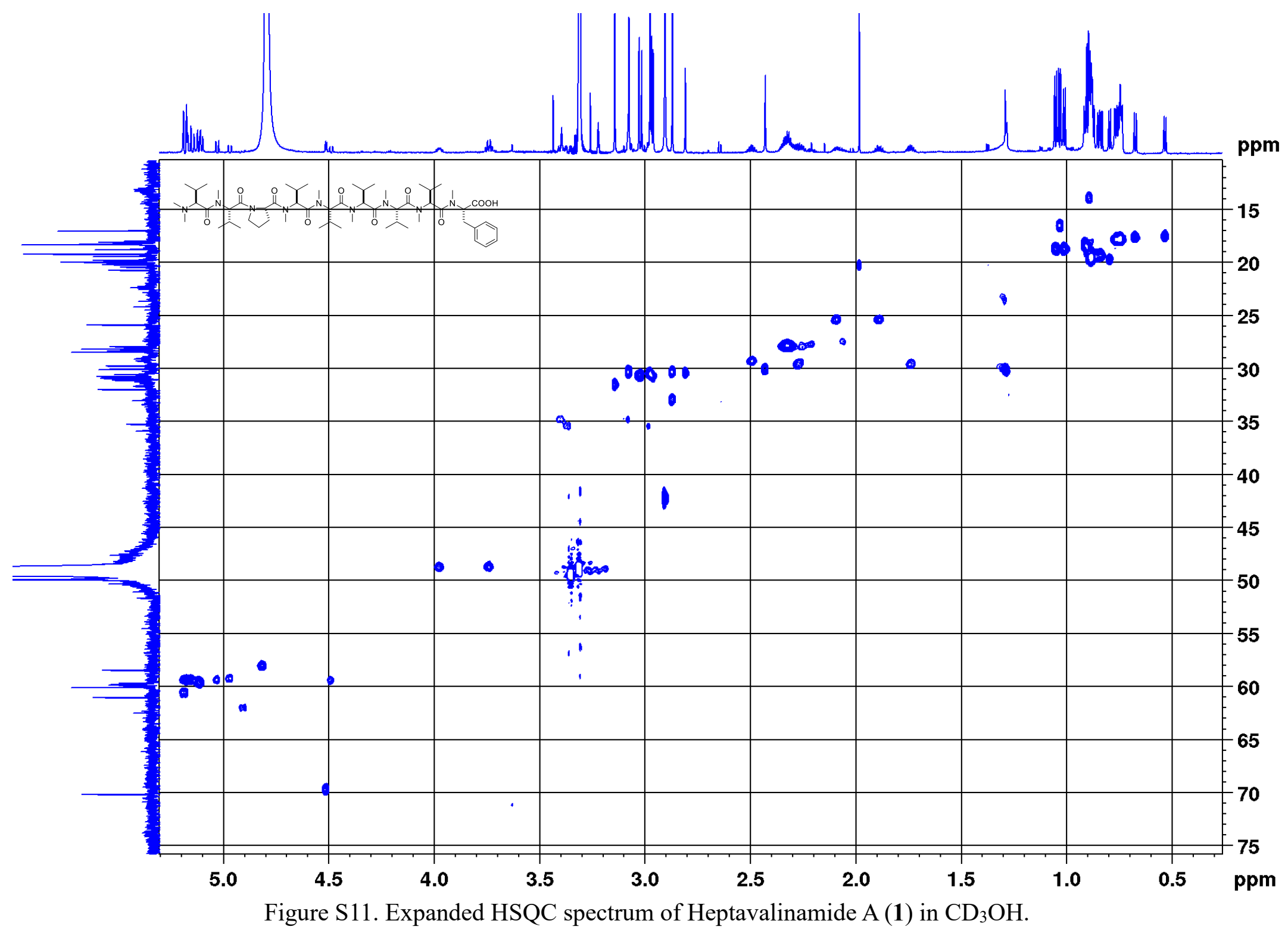




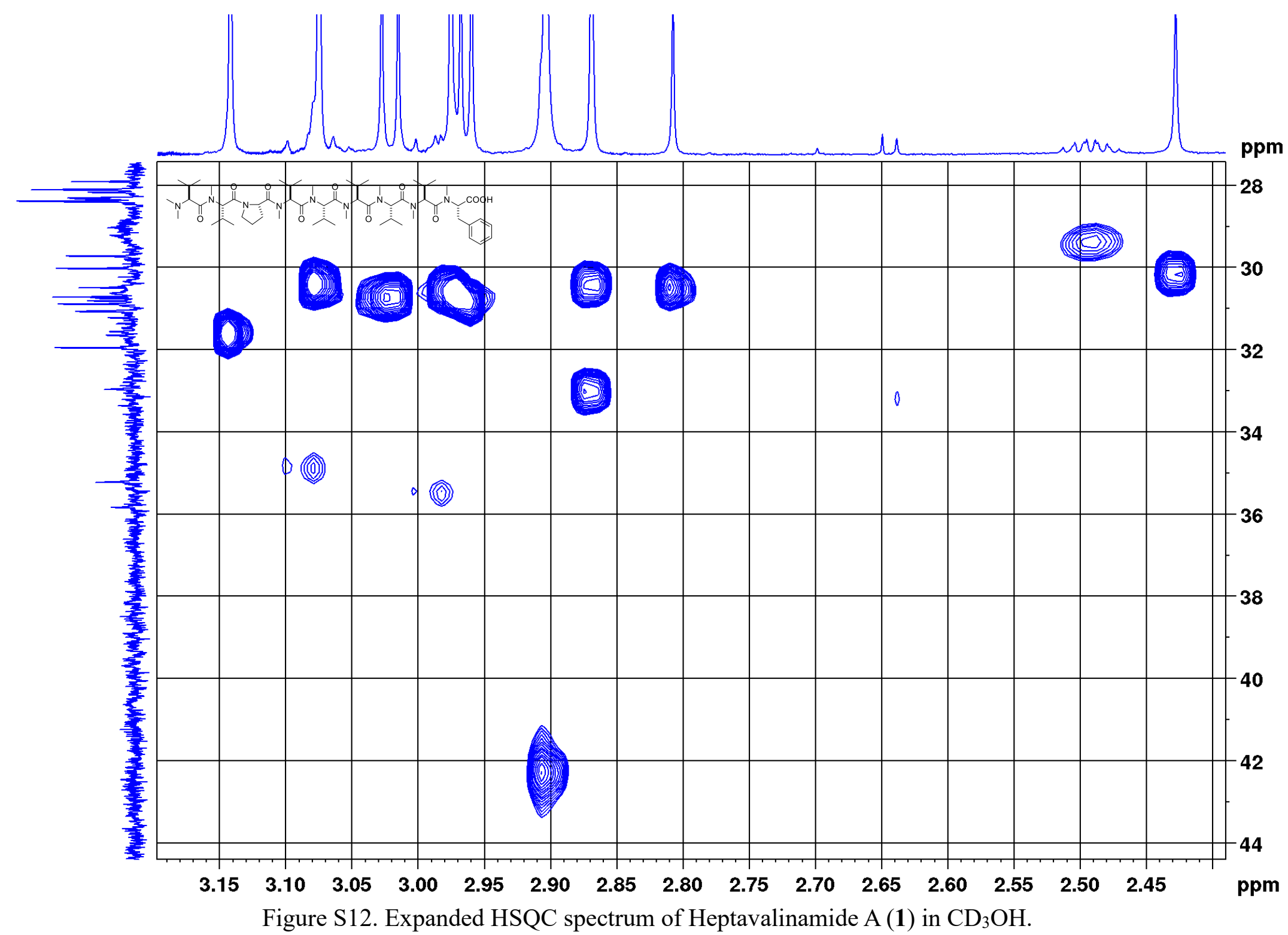




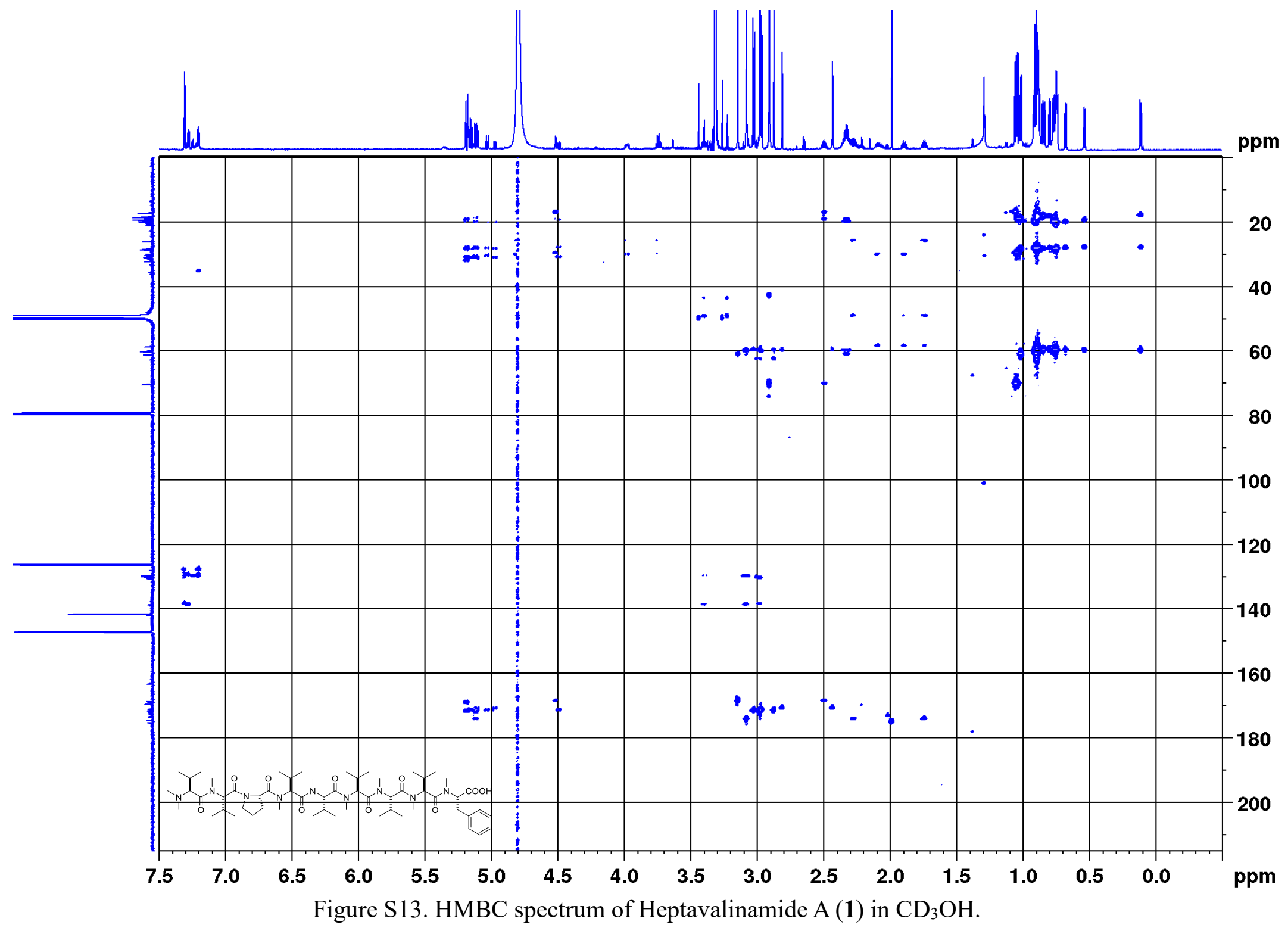




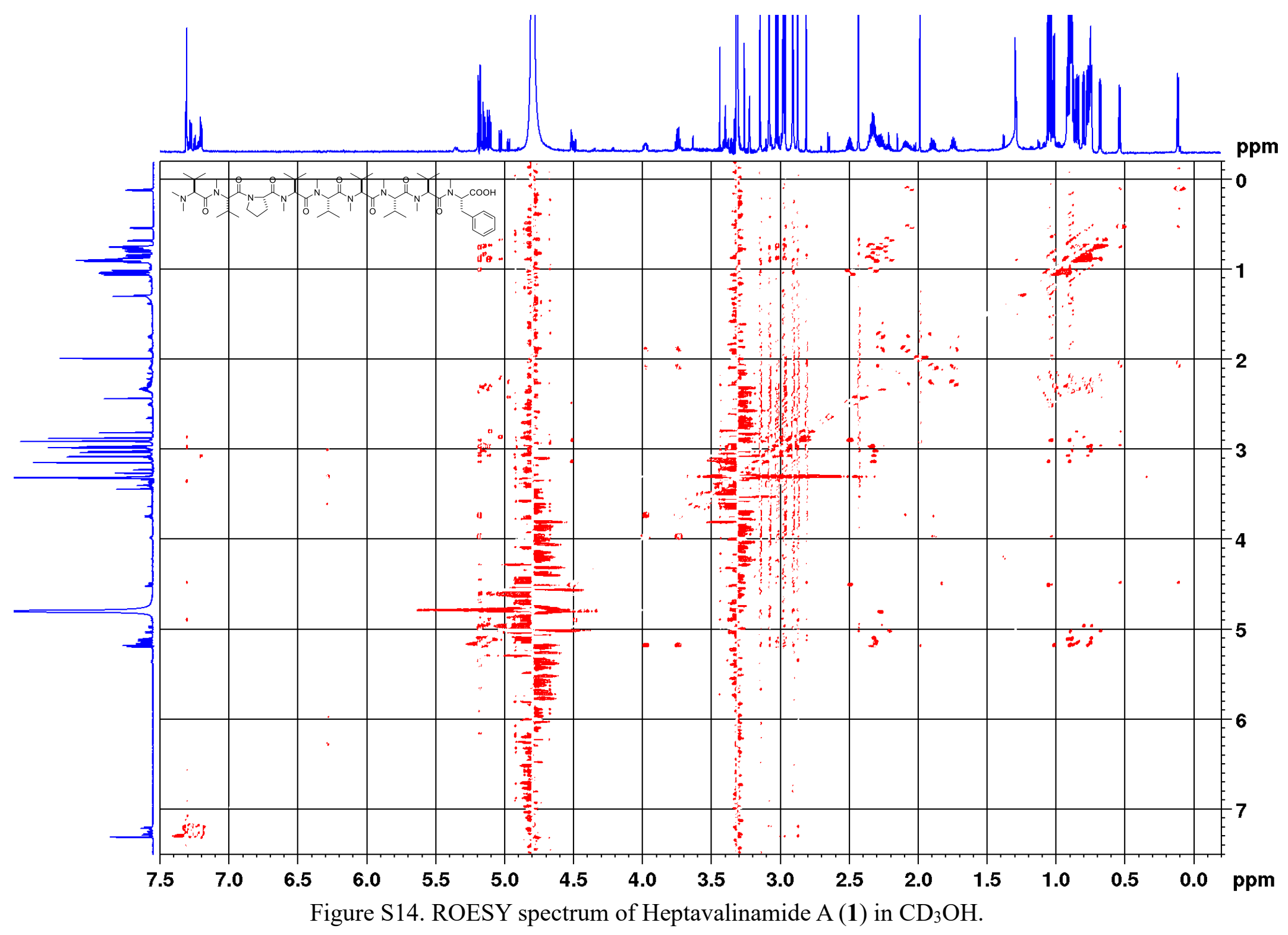




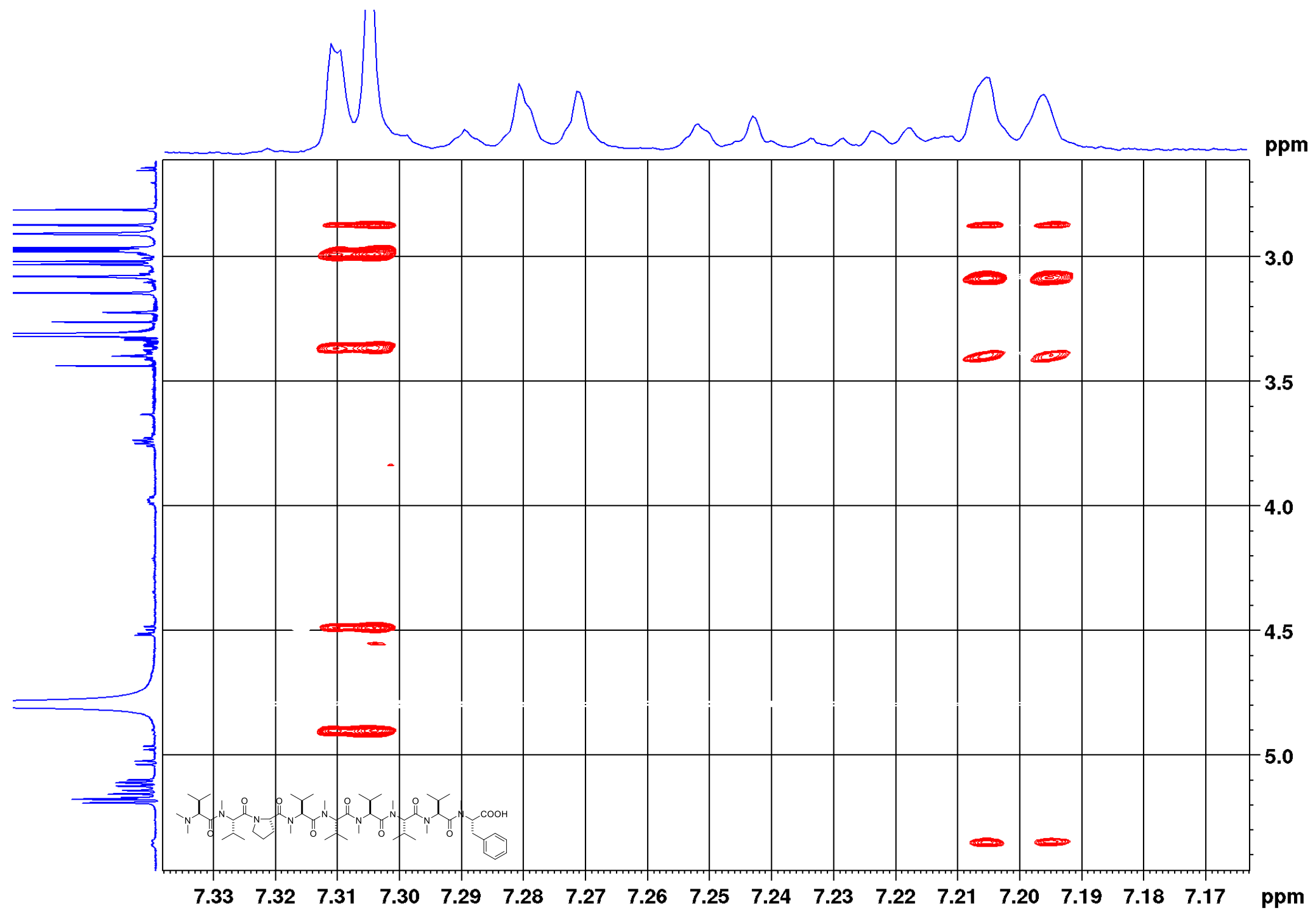

Figure S15. Expanded ROESY spectrum of Heptavalinamide A (1) in $\mathrm{CD}_{3} \mathrm{OH}$. 


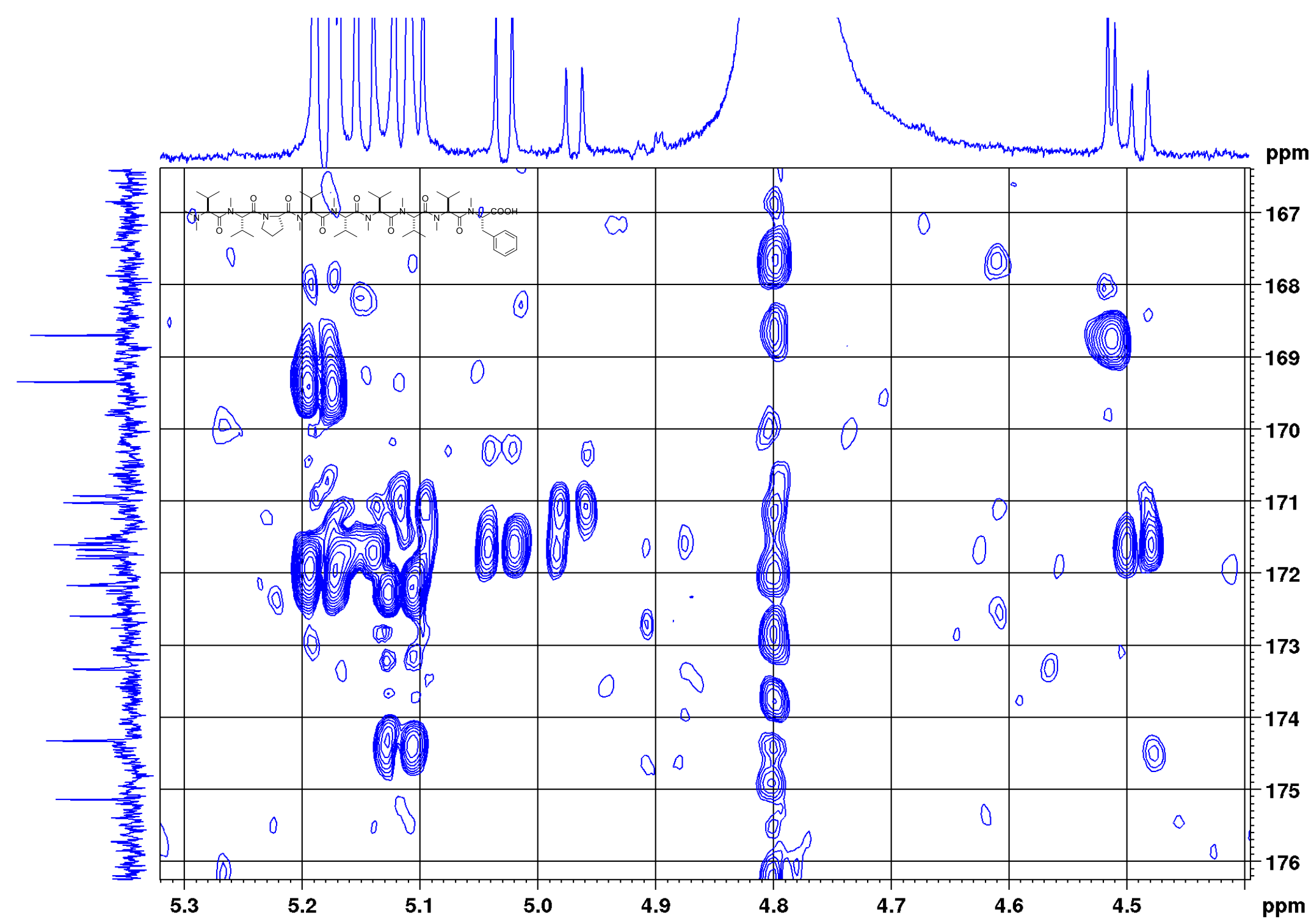

Figure S16. HMBC cross-peaks between the $\mathrm{H} \alpha$ region and amide carbonyl carbons of Heptavalinamide $\mathrm{A}(\mathbf{1})$ in $\mathrm{CD}_{3} \mathrm{OH}$. 


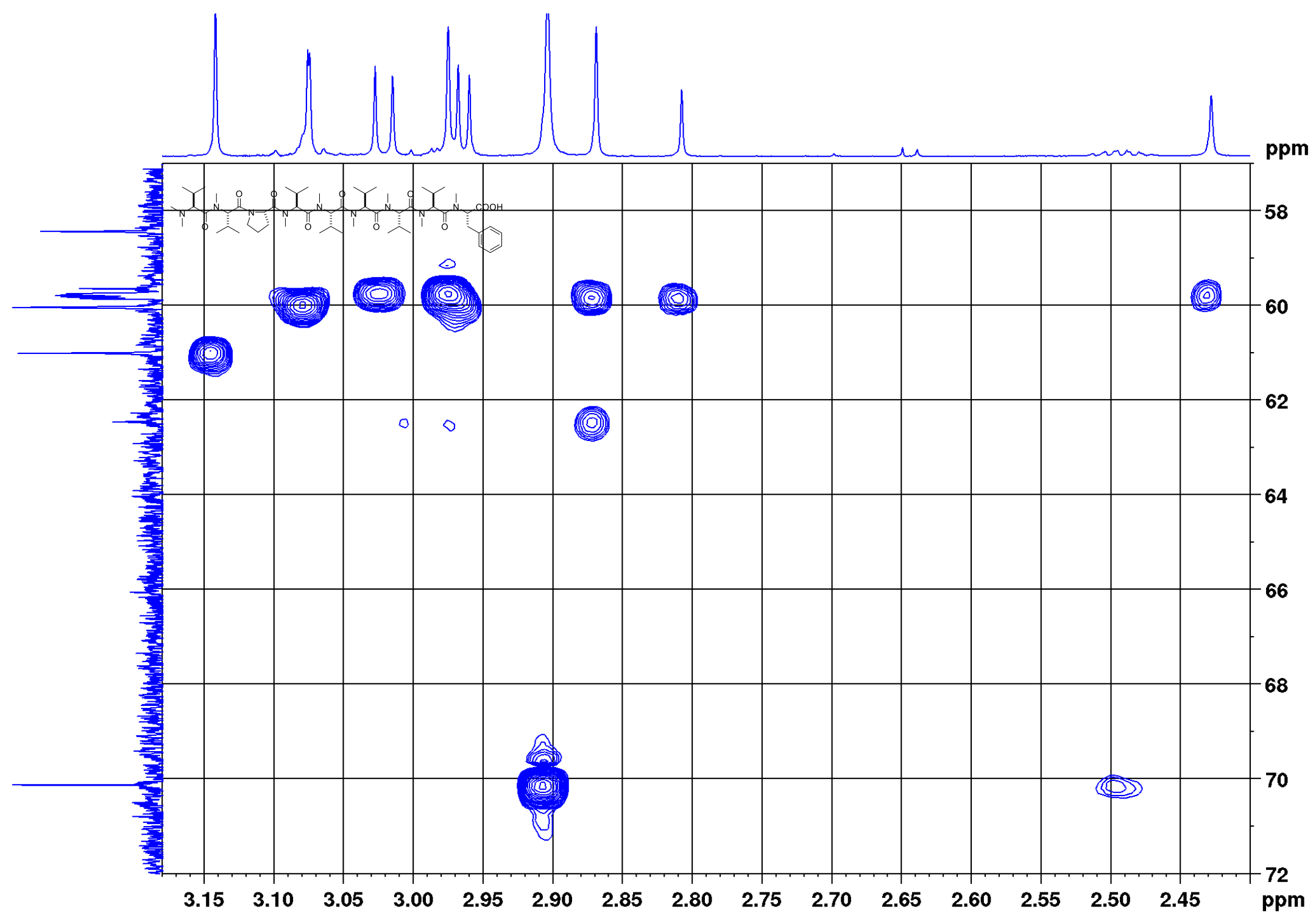

Figure S17. HMBC cross-peaks between the $N$-methyl proton and $\mathrm{C} \alpha$ region of Heptavalinamide $\mathrm{A}(1)$ in $\mathrm{CD}_{3} \mathrm{OH}$. 


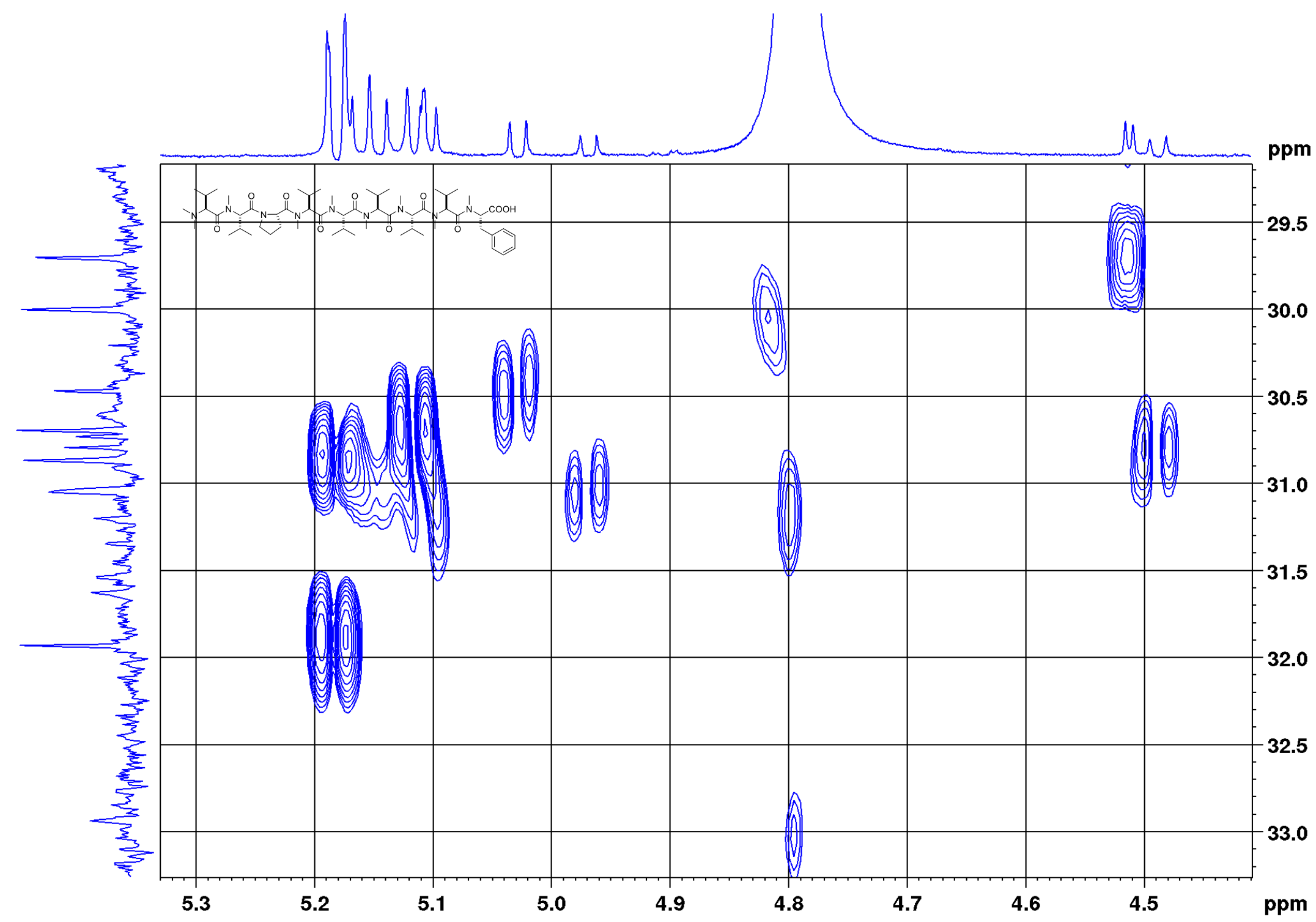

Figure S18. HMBC cross-peaks between the $\mathrm{H} \alpha$ region and $N$-methyl carbons of Heptavalinamide $\mathrm{A}(\mathbf{1})$ in $\mathrm{CD}_{3} \mathrm{OH}$. 


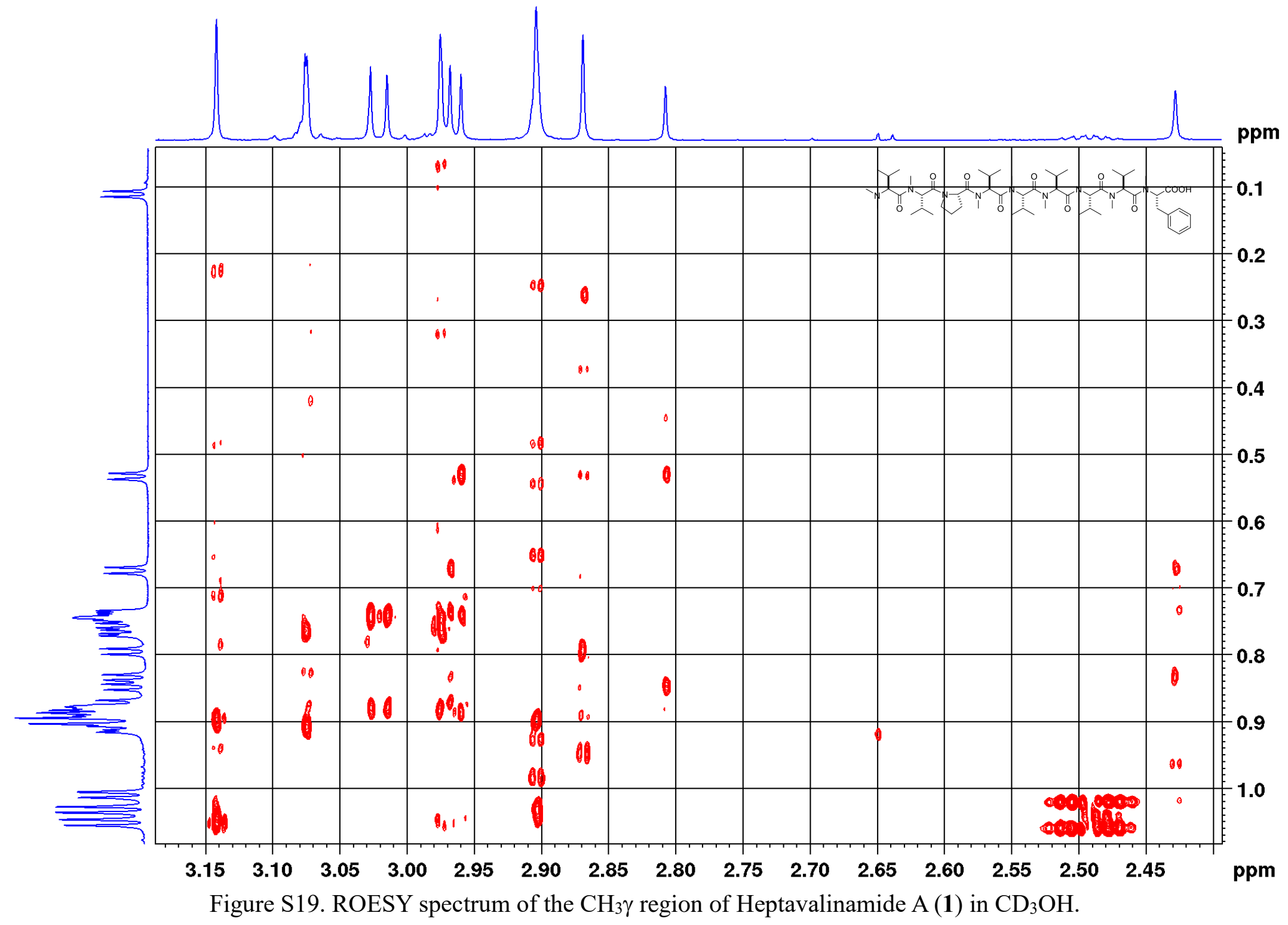




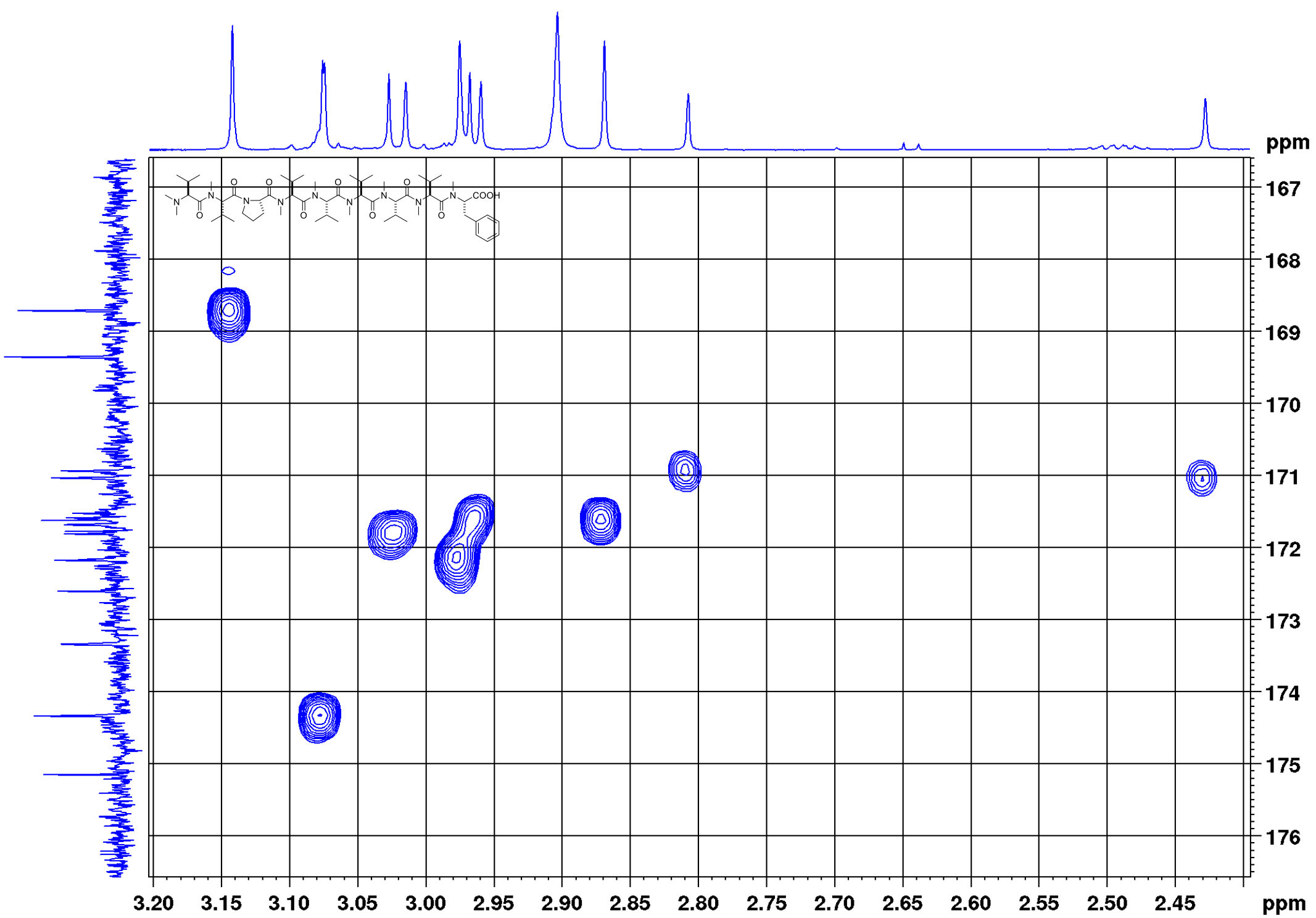

Figure S20. HMBC cross-peaks between the $N$-methyl proton and amide carbonyl carbons of Heptavalinamide $\mathrm{A}(\mathbf{1})$ in $\mathrm{CD}_{3} \mathrm{OH}$. 


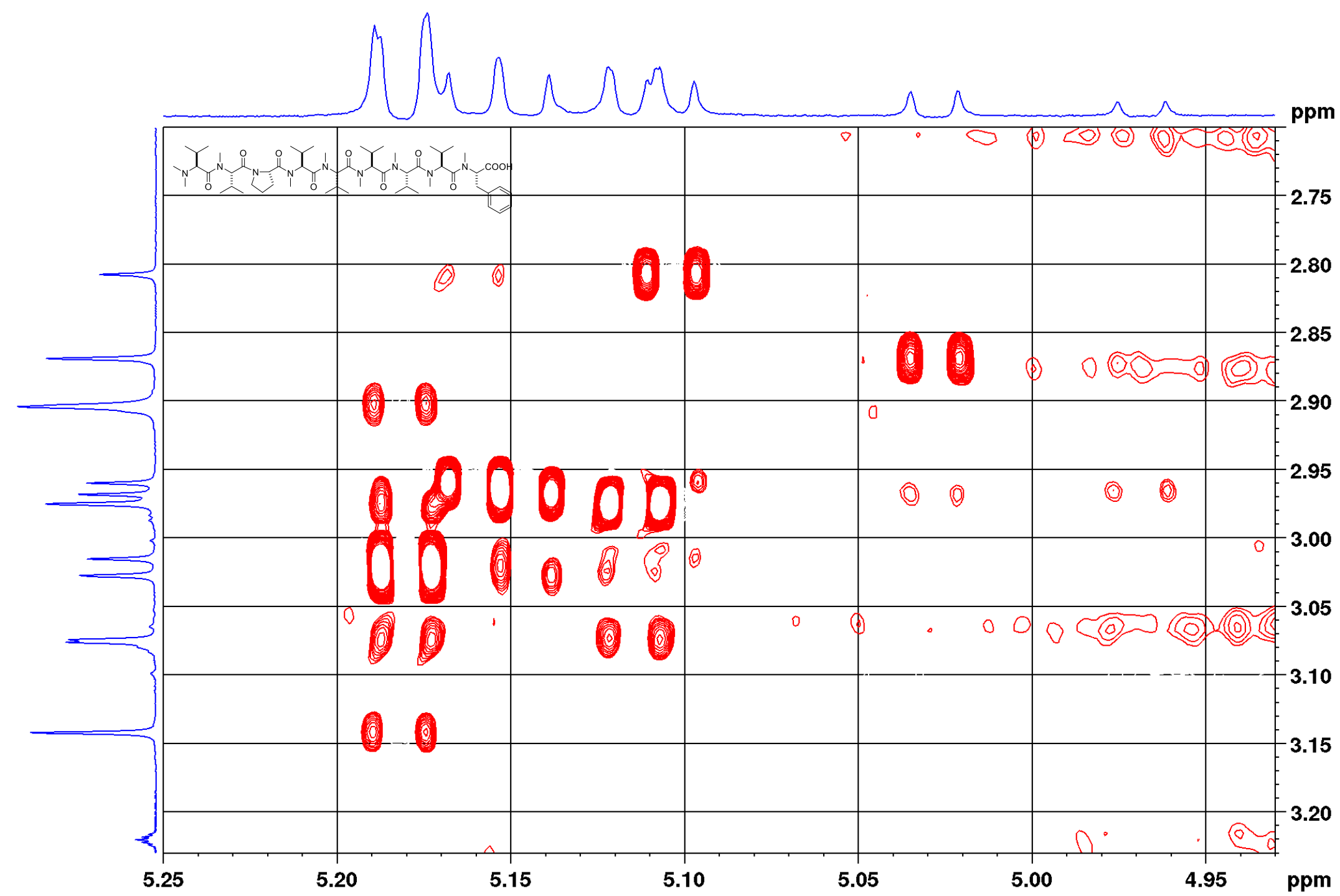

Figure S21. ROESY cross-peaks between the $N$-methyl proton and $\mathrm{C} \alpha$ region of Heptavalinamide $\mathrm{A}(\mathbf{1})$ in $\mathrm{CD}_{3} \mathrm{OH}$. 


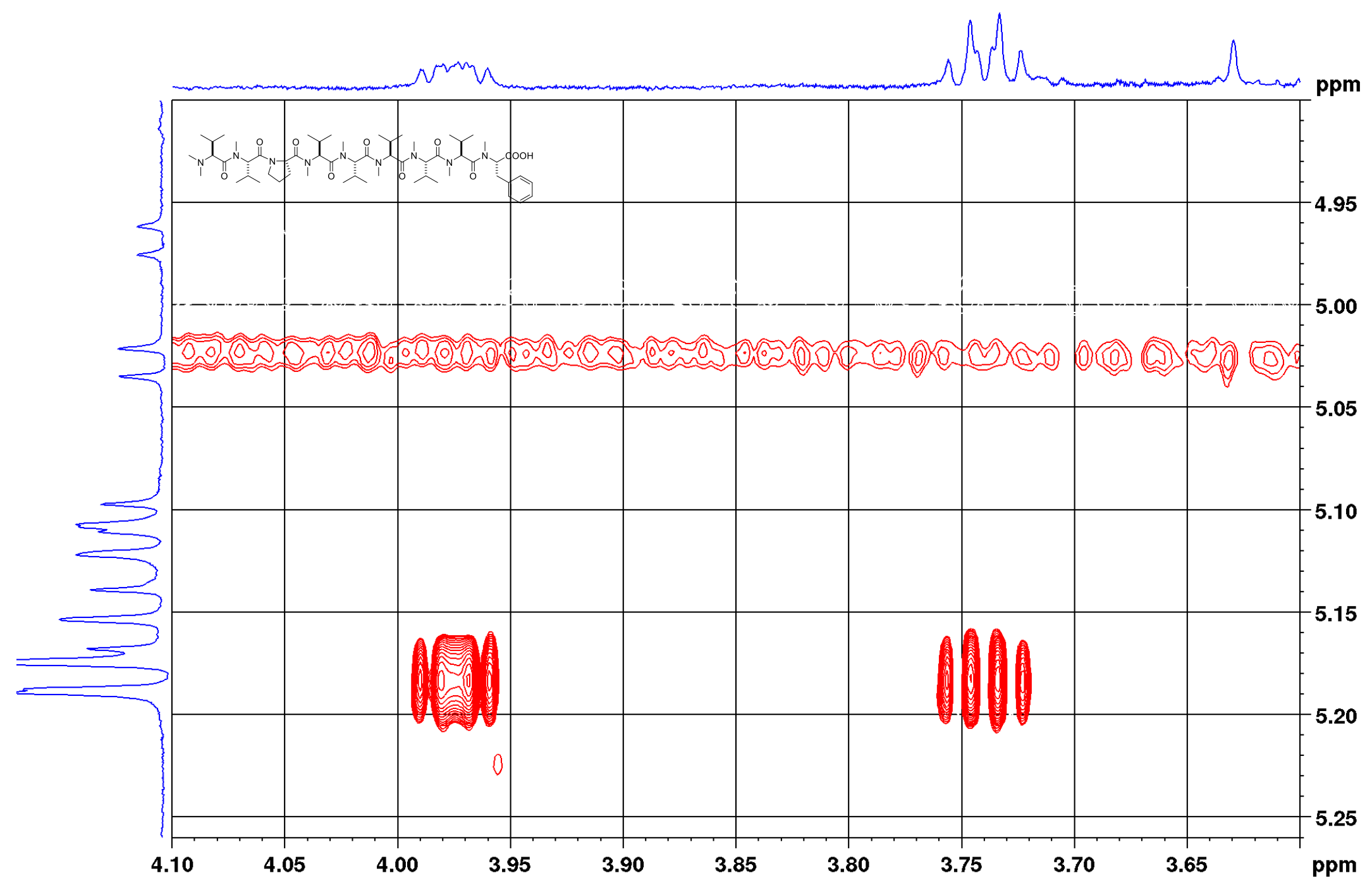

Figure S22. ROESY cross-peaks between the $\mathrm{H}_{2} \delta$ and $\mathrm{C} \alpha$ region of Heptavalinamide $\mathrm{A}(\mathbf{1})$ in $\mathrm{CD}_{3} \mathrm{OH}$. 


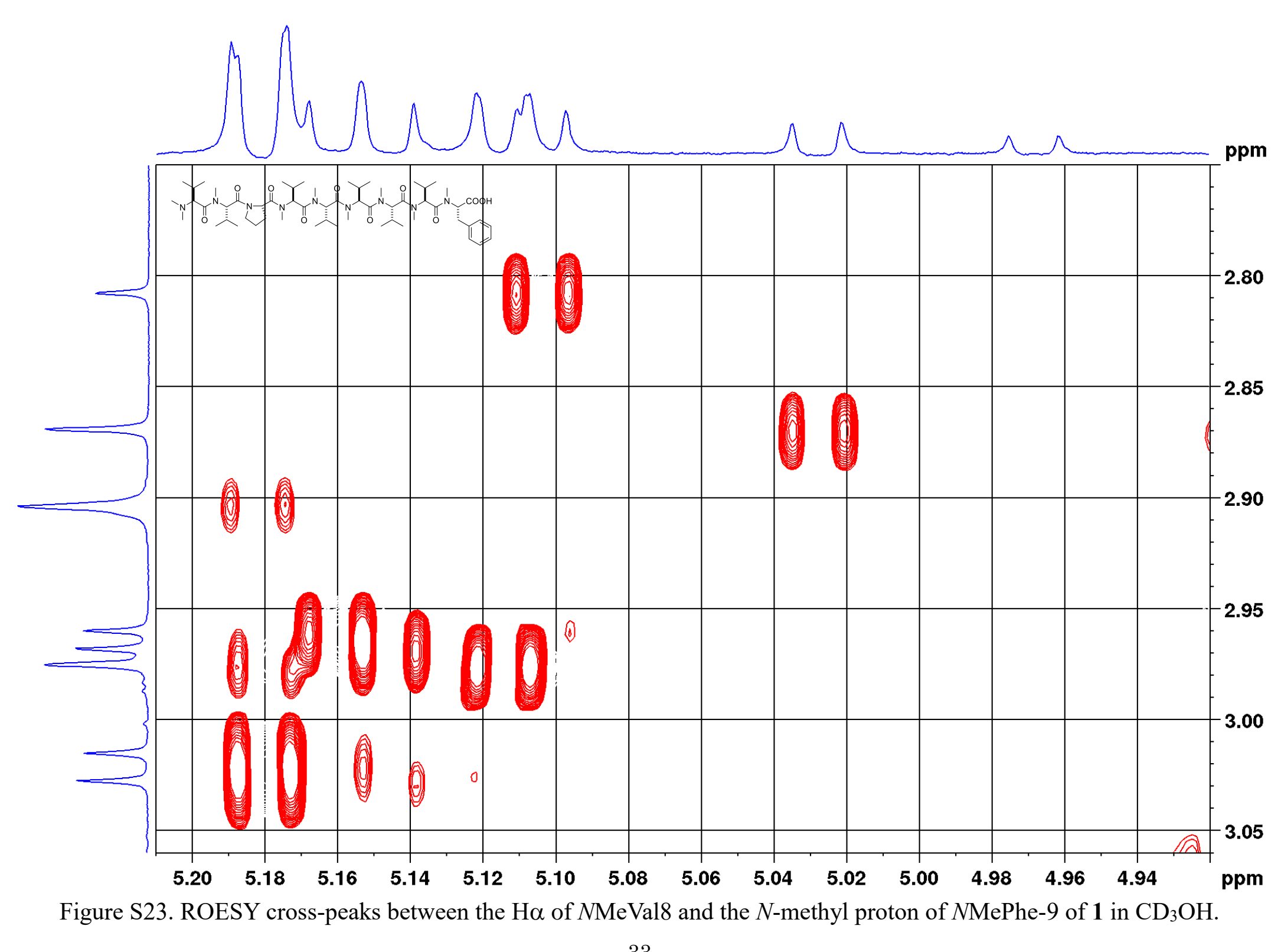




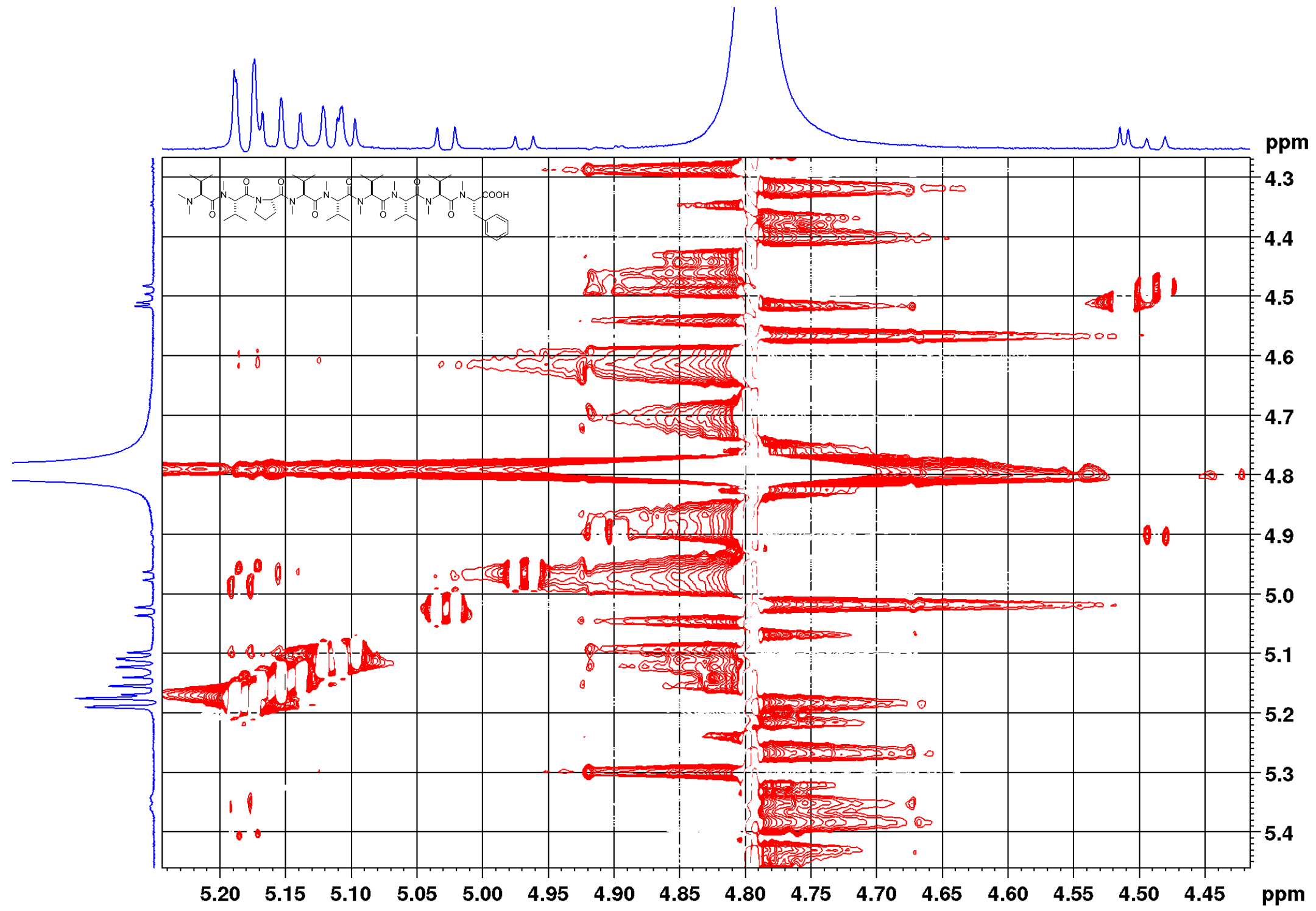

Figure S24. ROESY cross-peaks between the $\mathrm{H} \alpha$ of $N \mathrm{MeVal} 8$ and the $\mathrm{H} \alpha$ of $N \mathrm{MePhe}-9$ of $\mathbf{1}$ in $\mathrm{CD}_{3} \mathrm{OH}$. 

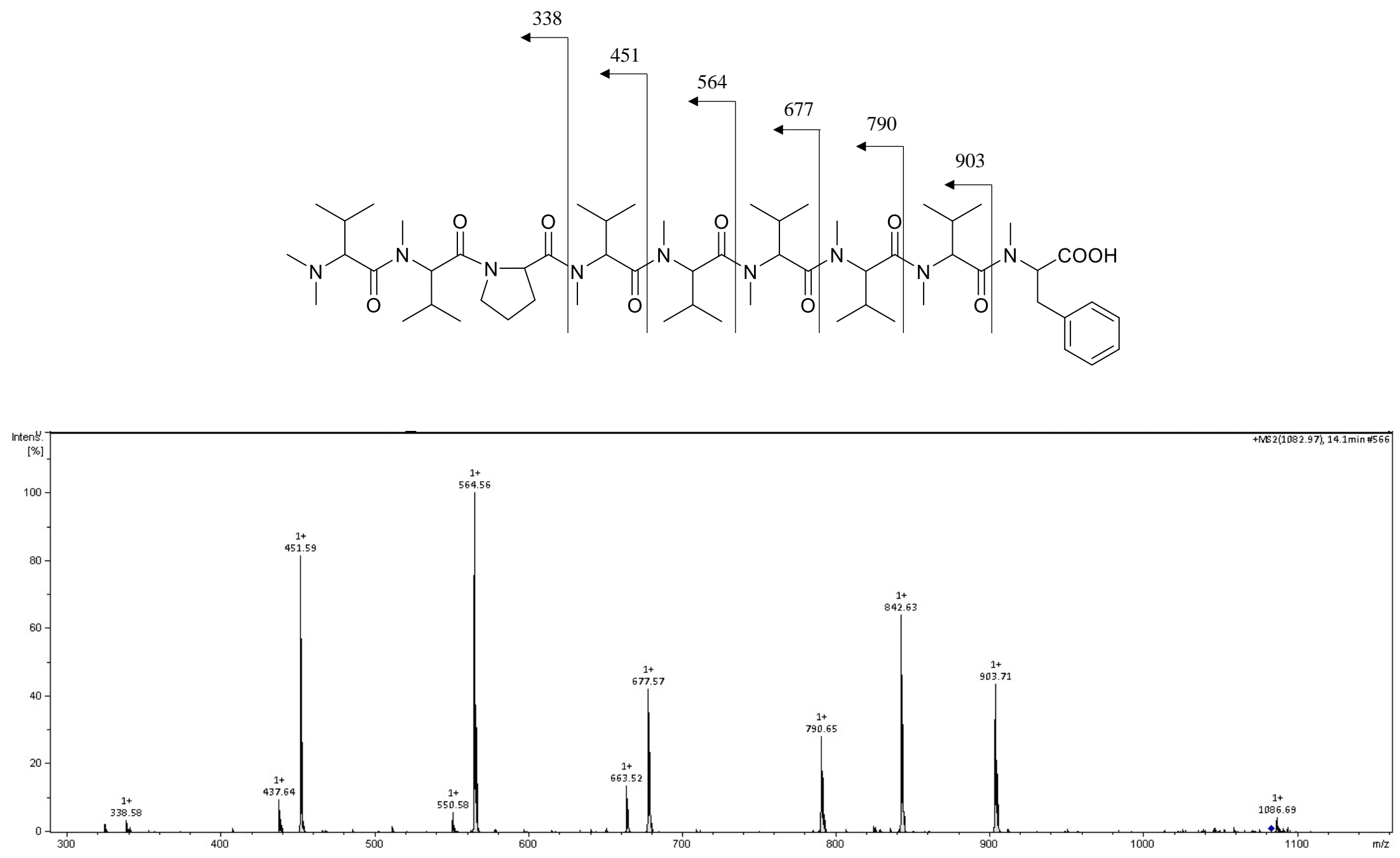

Figure S25. ESIMS/MS spectrum of Heptavalinamide A (1). 


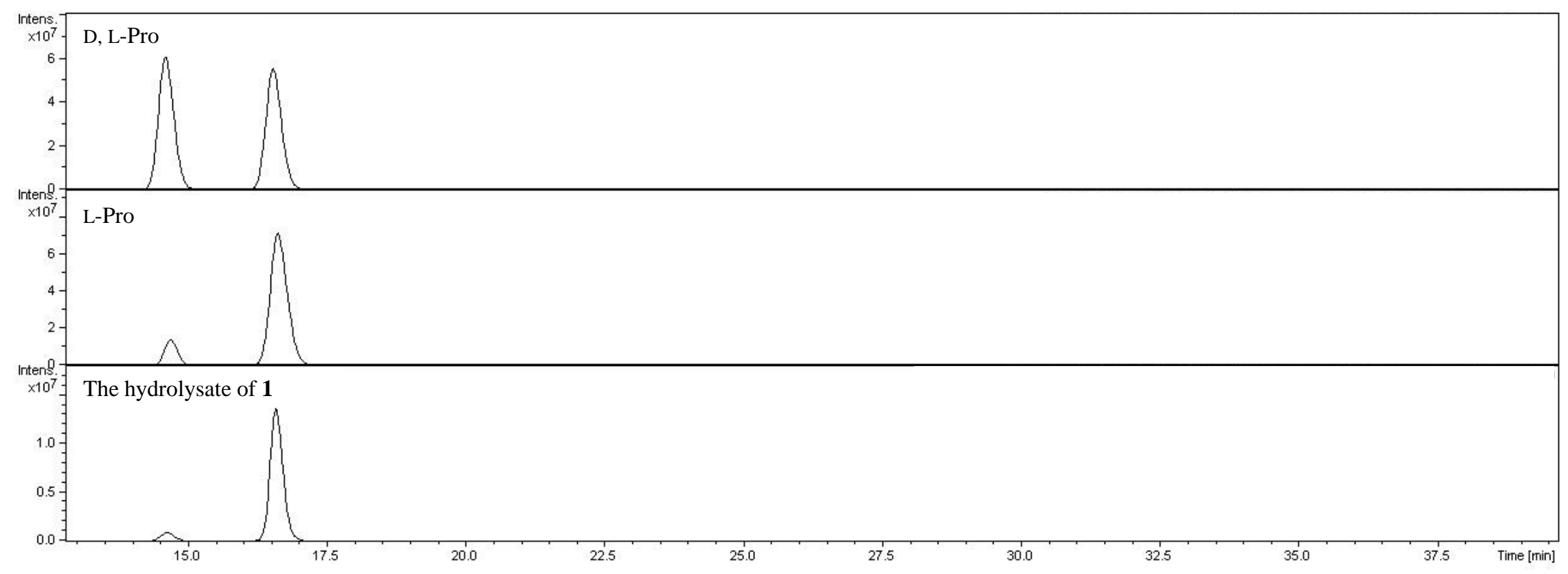

Figure S26. LCMS chart of Marfey's analysis of Heptavalinamide A (1).

The ratios of L-Pro and D-Pro were as follows: standard L-Pro (89:11); hydrolysate of 1 (92:8)

${ }^{a}$ In this analysis the purity of the Marfey's reagent was ca. $90 \%$ as obvious from the chromatograms of the standard L-Pro. It was possible to assign the configuration of the hydrolysate as L from the almost identical ratio of 9:1 between L-Pro and D-Pro. 


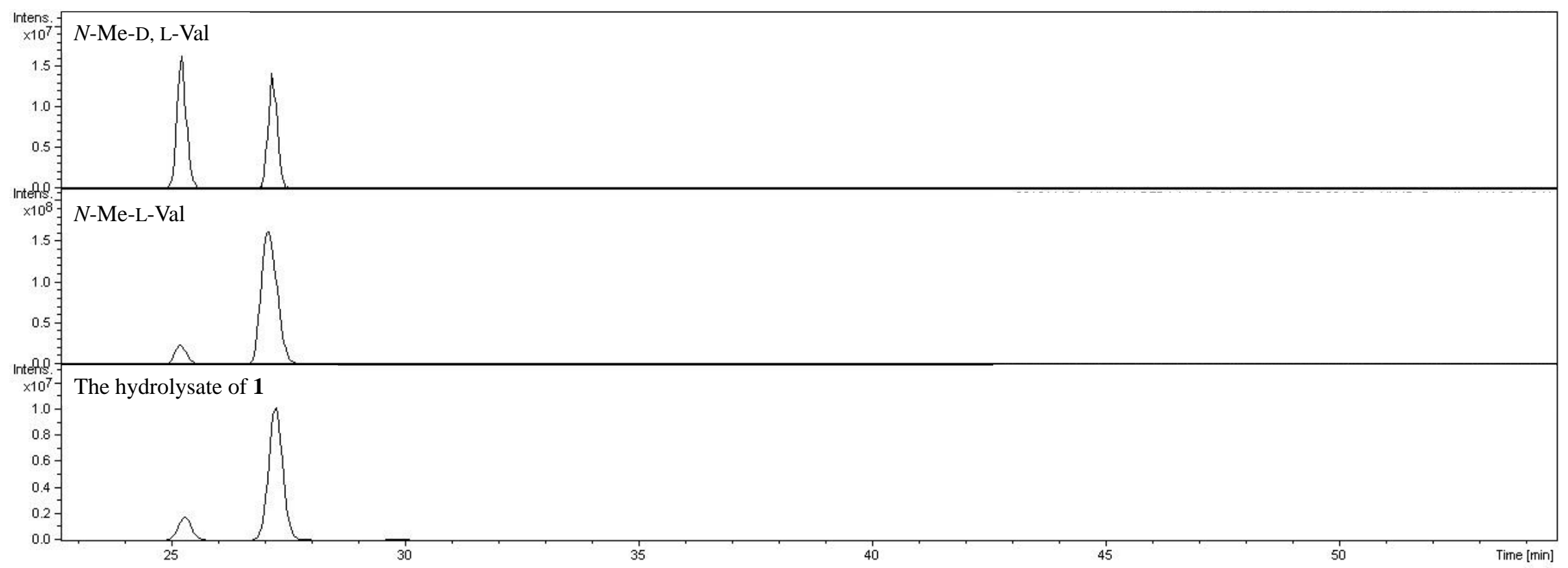

Figure S27. LCMS chart of Marfey's analysis of Heptavalinamide A (1).

The ratios of L- and D-NMeVal were as follows: standard L- NMeVal (90:10); hydrolysate of 1 (87:13) (cf. foot note for Fig S26) 


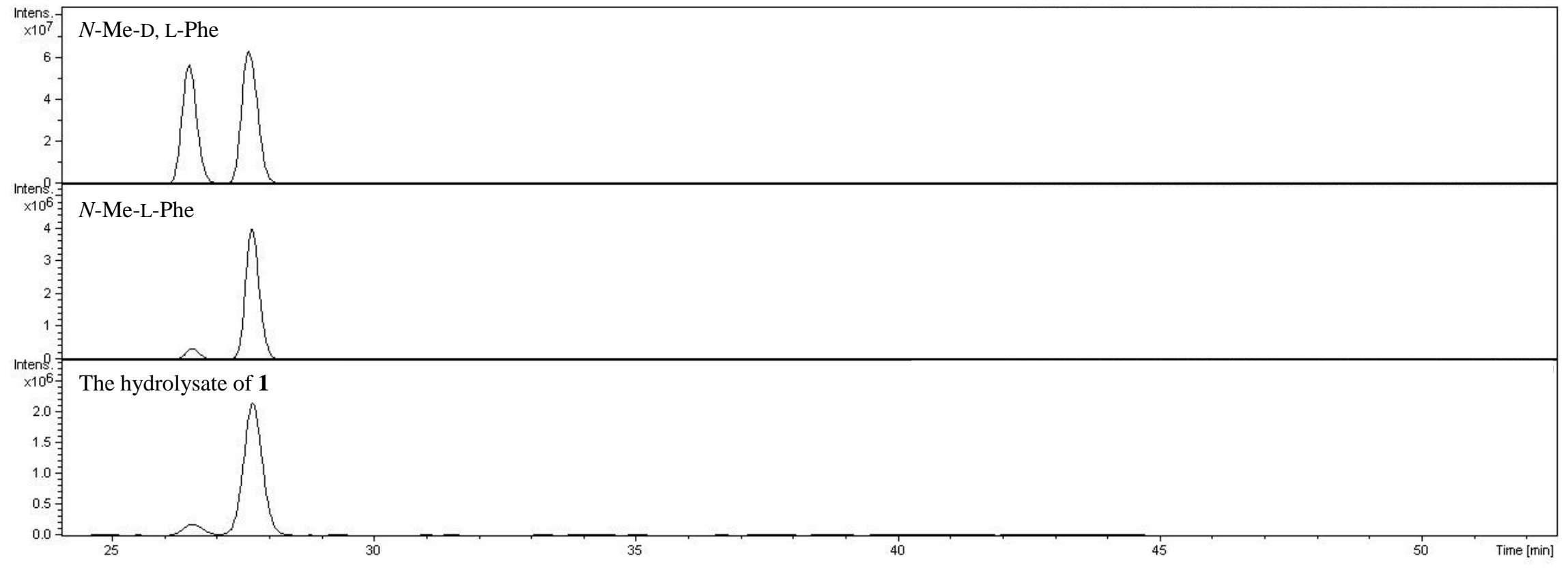

Figure S28. LCMS chart of Marfey's analysis of Heptavalinamide A (1).

The ratios of L- and D-NMePhe were as follows: standard L- NMePhe (92:8); hydrolysate of 1 (90:10) (cf. foot note for Fig S26) 


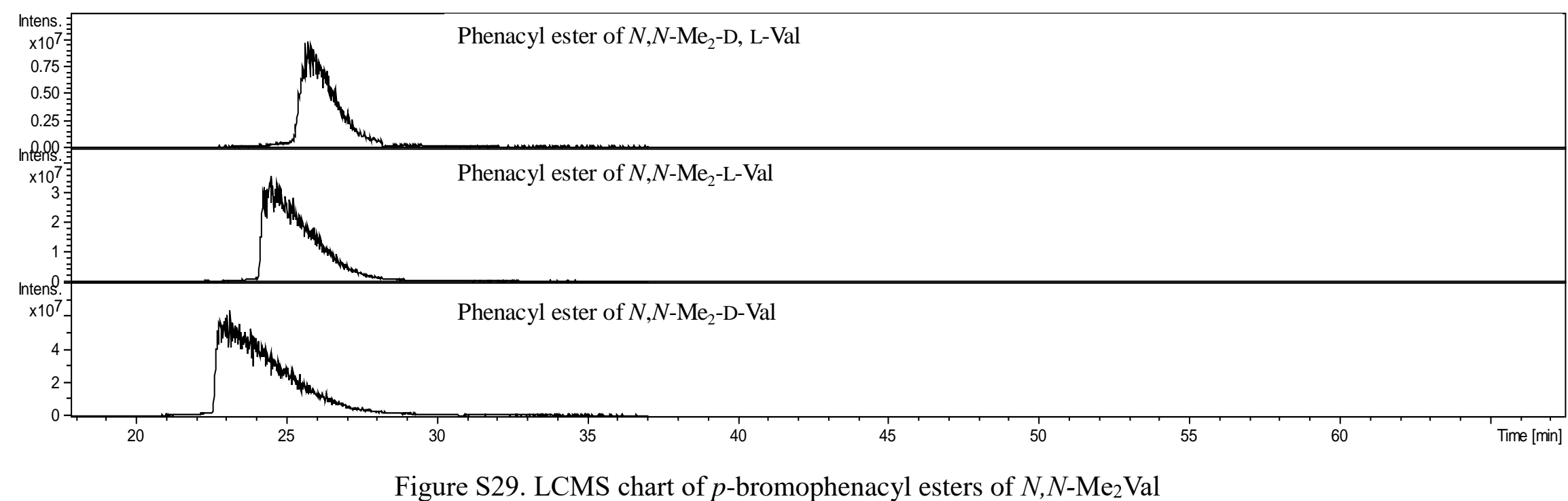

Figure S29. LCMS chart of $p$-bromophenacyl esters of $N, N-\mathrm{Me}_{2}$ Val 
L $\quad$ D

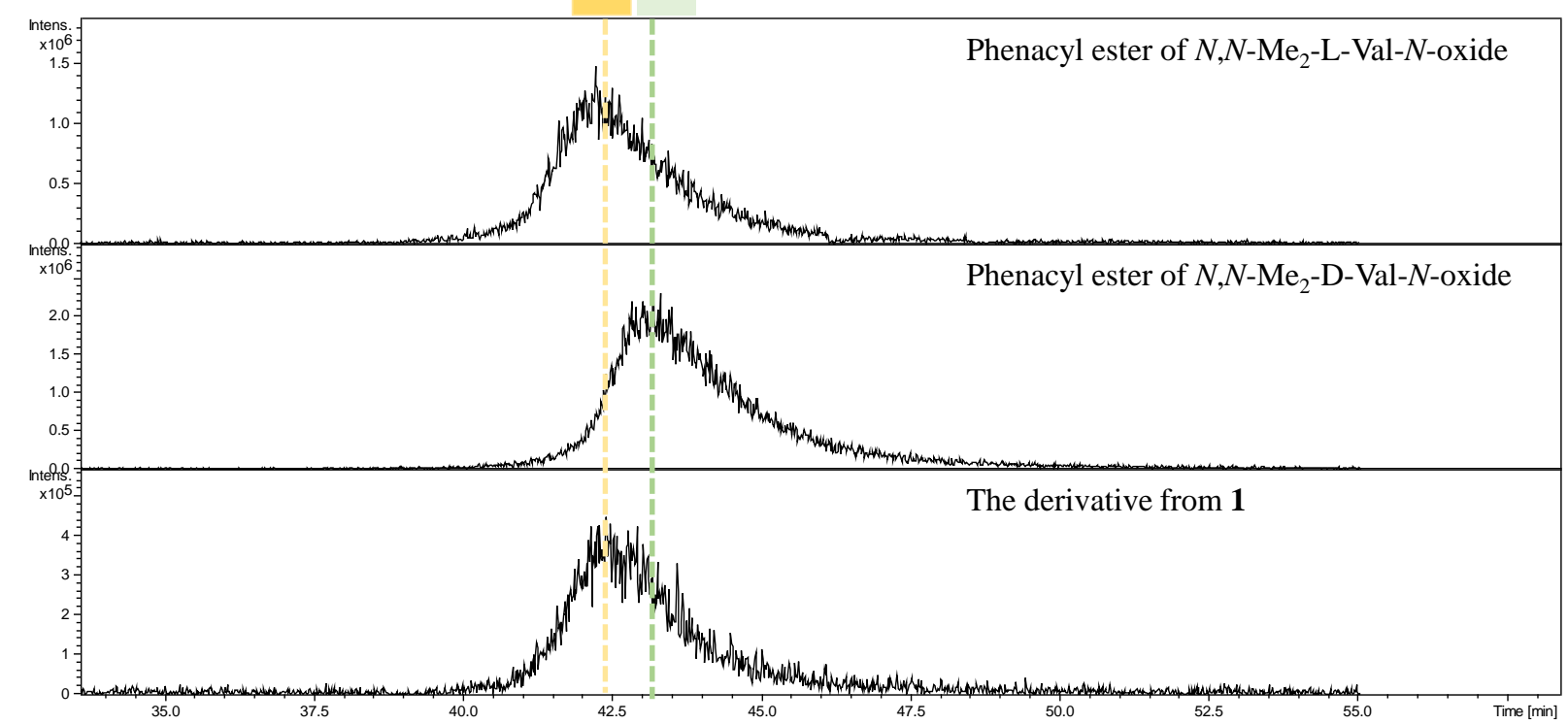

Figure S30. LCMS chart of $p$-bromophenacyl esters of $N, N-\mathrm{Me}_{2} \mathrm{Val}-N$-oxide. 